\title{
Effects of ATR-2 Irradiation to High Fluence on Nine RPV Surveillance Materials
}

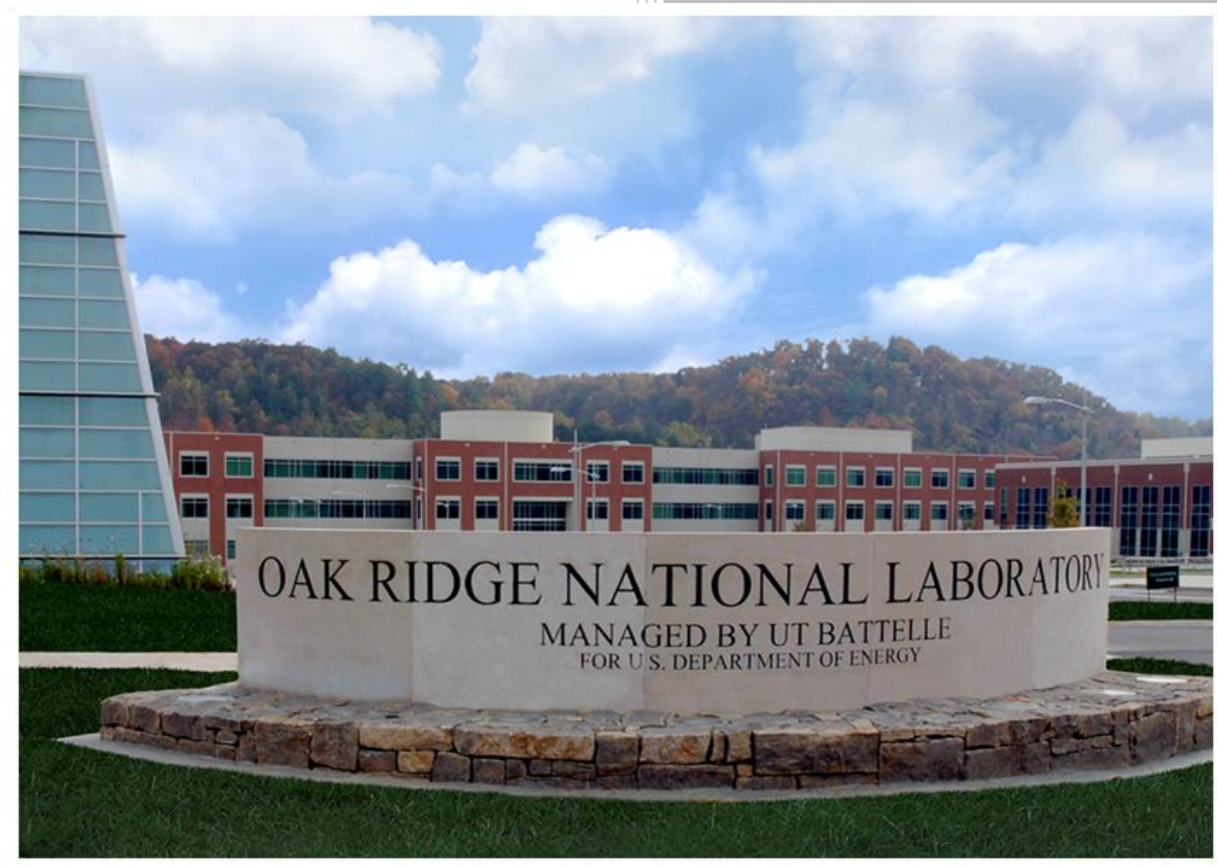

Approved for public release.

Distribution is unlimited.
R. K. Nanstad'1, G. R. Odette'2, N. Almirall'2, J. P. Robertson 3 , W. L. Server ${ }^{4}$, T. Yamamoto 2 , P. Wells ${ }^{2}$ ${ }^{1}$ R\&S Consulting 2University of California Santa Barbara

${ }^{3}$ Materials Science and Technology Division, Oak Ridge National Laboratory ${ }^{4}$ ATI-Consulting

\section{April 2017}




\title{
DOCUMENT AVAILABILITY
}

Reports produced after January 1, 1996, are generally available free via US Department of Energy (DOE) SciTech Connect.

Website http://www.osti.gov/scitech/

Reports produced before January 1, 1996, may be purchased by members of the public from the following source:

\author{
National Technical Information Service \\ 5285 Port Royal Road \\ Springfield, VA 22161 \\ Telephone 703-605-6000 (1-800-553-6847) \\ TDD 703-487-4639 \\ Fax 703-605-6900 \\ E-mail info@ntis.gov \\ Website http://www.ntis.gov/help/ordermethods.aspx
}

Reports are available to DOE employees, DOE contractors, Energy Technology Data Exchange representatives, and International Nuclear Information System representatives from the following source:

Office of Scientific and Technical Information

PO Box 62

Oak Ridge, TN 37831

Telephone 865-576-8401

Fax 865-576-5728

E-mail reports@osti.gov

Website http://www.osti.gov/contact.html

This report was prepared as an account of work sponsored by an agency of the United States Government. Neither the United States Government nor any agency thereof, nor any of their employees, makes any warranty, express or implied, or assumes any legal liability or responsibility for the accuracy, completeness, or usefulness of any information, apparatus, product, or process disclosed, or represents that its use would not infringe privately owned rights. Reference herein to any specific commercial product, process, or service by trade name, trademark, manufacturer, or otherwise, does not necessarily constitute or imply its endorsement, recommendation, or favoring by the United States Government or any agency thereof. The views and opinions of authors expressed herein do not necessarily state or reflect those of the United States Government or any agency thereof. 
Light Water Reactor Sustainability

\title{
Effects of ATR-2 Irradiation to High Fluence on Nine RPV Surveillance Materials
}

\author{
R. K. Nanstad ${ }^{1}$, G. R. Odette ${ }^{2}$, N. Almirall ${ }^{2}$, J. P. Robertson ${ }^{1}$, W. L. Server ${ }^{3}$, \\ T. Yamamoto ${ }^{2}$, and P. Wells ${ }^{2}$, \\ ${ }^{1} \mathrm{R} \& S$ Consultants, ${ }^{2}$ University of California Santa Barbara, \\ ${ }^{3}$ Materials Science and Technology Division, Oak Ridge National Laboratory \\ ${ }^{4}$ ATI-Consulting
}

Date Published: December 2016

Prepared under the direction of the

U.S. Department of Energy

Office of Nuclear Energy

Light Water Reactor Sustainability

Materials Aging and Degradation Pathway

Prepared by

OAK RIDGE NATIONAL LABORATORY

Oak Ridge, TN 37831-6283

managed by

UT-BATTELLE, LLC

for the

US DEPARTMENT OF ENERGY

under contract DE-AC05-00OR22725 
This page intentionally left blank 


\section{CONTENTS}

\section{Page}

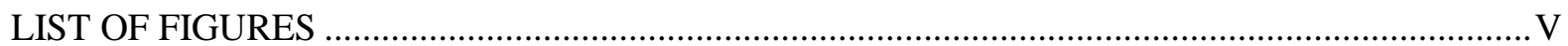

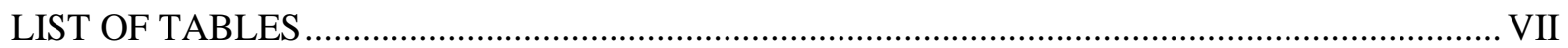

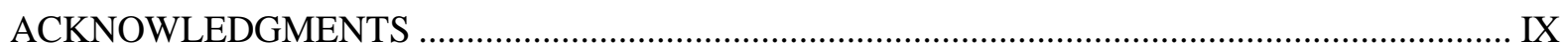

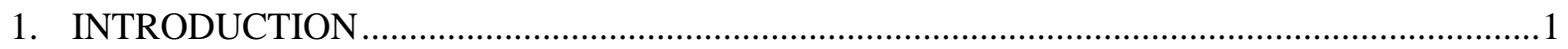

2. BACKGROUND AND REVIEW OF ATR-2 EXPERIMENT ….............................................2

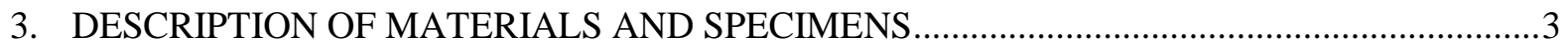

4. THE ATR-2 EXPERIMENT CAPSULE DISASSEMBLY ….............................................

5. POST-IRRADIATION EXAMINATION OF NINE ARCHIVAL SURVEILLANCE

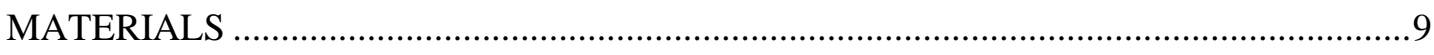

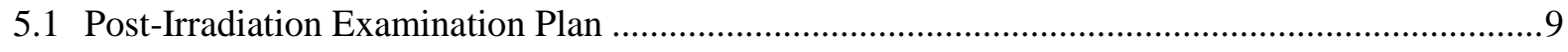

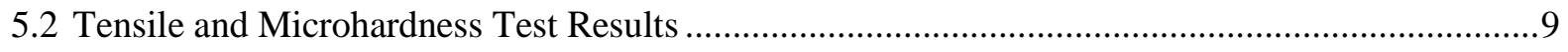

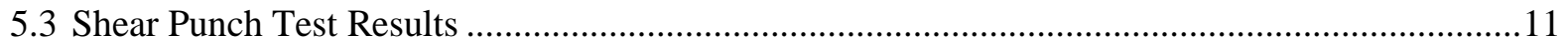

5.4 Comparison of Mechanical Property Results with Surveillance Data.........................................13

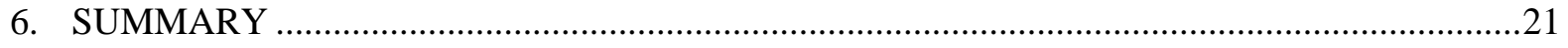

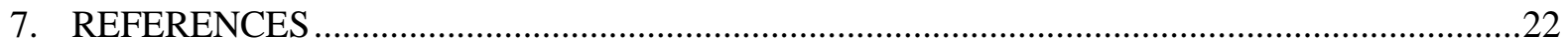

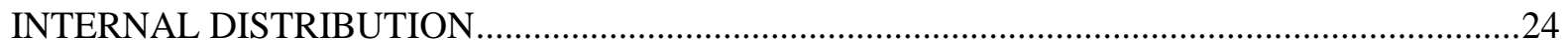

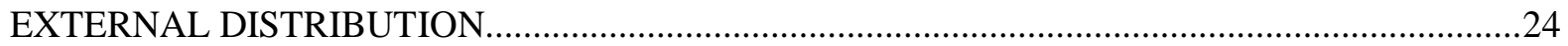


This page intentionally left blank 


\section{LIST OF FIGURES}

3.1 Content of major irradiation-sensitive chemical elements for nine commercial reactor surveillance materials in the UCSB ATR-2 experiment...

3.2 Schematic diagram of multi-purpose disc specimen with diameter and thickness indicated.

3.3 Schematic diagram showing concept for loading of 8-mm multi-purpose disc specimens into the sub-capsule holders.

3.4 Schematic of the tensile loading box (left) and SSJ-2 tensile specimens (right). Note that half of the specimens have a gauge length of $5.00 \mathrm{~mm}$ (showed), while the others have a $2.2 \mathrm{~mm}$ gauge length. Yield strength from tensile specimens $\left(\sigma_{\mathrm{y}}\right)$ vs shear punch $\left(\tau_{\mathrm{y}}\right)$ tests indicating an excellent correlation for steels with a wide range of yield strengths showing the empirical relation $\sigma_{\mathrm{y}} \approx 1.77 \tau_{\mathrm{y}}[13]$

5.1 Example stress-strain curve with $0.2 \%$ offset line. Change in tensile yield stress versus change in microhardness for a subset of surveillance alloys in cup 7 [14].

5.4 Power law (a) and linear (b) fits to data from original equations in [14] for $\Delta \sigma_{y}$, to $\Delta \mathrm{TT}_{41 \mathrm{~J}}$

5.5 Charpy 41-J shifts vs yield strength changes for (a) weld metal and (b) base metal surveillance data for the nine surveillance materials

5.6 Tensile yield strength from surveillance reports with linear curve fits (a), and estimated room temperature yield strength increases vs fluence compared with ATR-2 results (b), for Material F, the lower copper Weld Heat 1P3571.

5.7 Irradiation-induced Charpy 41-J transition temperature shifts for measured surveillance data and for the predicted shifts from the ATR-2 experiment for Material A, Weld Heat 33A277..

5.8 Irradiation-induced Charpy 41-J transition temperature shifts for measured surveillance data and for the predicted shifts from the ATR-2 experiment for Material B, SA533B-1 Plate, Heat C7466-1.

5.9 Irradiation-induced Charpy 41-J transition temperature shifts for measured surveillance data and for the predicted shifts from the ATR-2 experiment for Material C, SA508-2 Forging Heat 123X167VA1.

5.10 Irradiation-induced Charpy 41-J transition temperature shifts for measured surveillance data and for the predicted shifts from the ATR-2 experiment for Material D, Weld Heat 1P3571, Linde 1092 Weld-M, Higher Copper.

5.11 Irradiation-induced Charpy 41-J transition temperature shifts for measured surveillance data and for the predicted shifts from the ATR-2 experiment for Material E, SA533B-1 Heat C0544-2, Plate B9004-2.

5.12 Irradiation-induced Charpy 41-J transition temperature shifts for measured surveillance data and for the predicted shifts from the ATR-2 experiment for Material F, Weld Heat 1P3571, Linde 1092 Weld-K, Lower Copper.

5.13 Irradiation-induced Charpy 41-J transition temperature shifts for measured surveillance data and for the predicted shifts from the ATR-2 experiment for Material G, Weld Heat BOLA. 
5.14 Irradiation-induced Charpy 41-J transition temperature shifts for measured surveillance data and for the predicted shifts from the ATR-2 experiment for Material H, Weld Heat 4P4784.

5.15 Irradiation-induced Charpy 41-J transition temperature shifts for measured surveillance data and for the predicted shifts from the ATR-2 experiment for

$5.16 \Delta \quad \Delta$ y versus fluence for the nine surveillance alloys with $<0.07 \mathrm{wt} . \% \mathrm{Cu}$ (left) and $>0.07 \mathrm{wt} . \% \mathrm{Cu}$ (right). [14]....

5.17 ATR-2 cup 7 hardening for various surveillance alloys along with predictions

from existing models. [14] 


\section{LIST OF TABLES}

2.1 Neutron flux, fluence $(\mathrm{E}>1 \mathrm{MeV})$ and temperature for the various cups in the

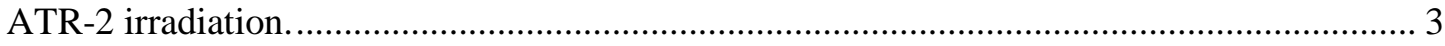

3.1 Specimen Matrices Summary for ATR-2 Experiment ...................................................... 4

3.2 List of archival surveillance materials supplied by Westinghouse and Florida

Power and Light for the ATR-2 Experiment........................................................................ 4

3.3 Chemical composition of archival commercial reactor surveillance materials....................... 5

5.1 Summary of microhardness testing for nine RPV surveillance materials............................ 11

5.2 Summary of shear punch testing for nine RPV surveillance materials................................. 12

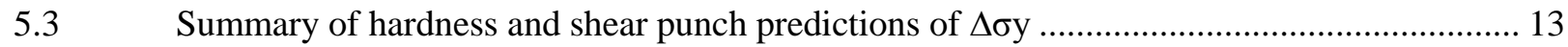


This page intentionally left blank 


\section{ACKNOWLEDGMENTS}

This research was sponsored jointly by the U.S. Department of Energy, Office of Nuclear Energy, for the Light Water Reactor Sustainability (LWRS) Program Research and Development Program, and the Electric Power Research Institute for contributing financially for testing of the surveillance materials. The authors extend their appreciation to Dr. Keith Leonard for LWRS programmatic support, to Mr. Tim Hardin of EPRI for financial support, and to Dr. Mikhail Sokolov and Dr. Xiang Chen for technical review. We also specifically acknowledge the major NSUF contributions of Rory Kennedy, Jim Cole, Brandon Miller, Collin Knight, Paul Murray, Joe Nielsen, Mitch Meyer, Mike Sprenger, Tom Maddock and other ATR National Scientific User Facility staff for conducting the UCSB ATR-2 irradiation, for disassembly of the irradiation capsule, and for shipping of the specimens to ORNL. Finally, we extend our appreciation to Mark Delph and the staff of the ORNL IMET hot cell facility (and previous facility manager Pat Bishop) for disassembly of the specimen cups and for packaging of specimens for shipment to the ORNL LAMDA laboratory and to UCSB. 
This page intentionally left blank 


\section{INTRODUCTION}

The reactor pressure vessel (RPV) in a light-water reactor (LWR) represents the first line of defense against a release of radiation in case of an accident. Thus, regulations that govern the operation of commercial nuclear power plants require conservative margins of fracture toughness, both during normal operation and under accident scenarios. In the unirradiated condition, the RPV has sufficient fracture toughness such that failure is implausible under any postulated condition, including pressurized thermal shock (PTS) in pressurized water reactors (PWR). In the irradiated condition, however, the fracture toughness of the RPV may be severely degraded, with the degree of toughness loss dependent on the radiation sensitivity of the materials. The available embrittlement predictive models, e.g. [1,2], and our present understanding of radiation damage are not fully quantitative, and do not treat all potentially significant variables and issues, particularly considering extension of operation to $80 \mathrm{y}$.

The major issues regarding irradiation effects are discussed in [3, 4] and have also been discussed in previous progress and milestone reports for the Light-Water Reactor Sustainability Program (LWRSP). As noted previously, of the many significant issues discussed, the issue considered to have the most impact on the current regulatory process is that associated with effects of neutron irradiation on RPV steels at high fluence, for long irradiation times, and as affected by neutron flux. It is clear that embrittlement of RPV steels is a critical issue that may limit LWR extended operation. The primary objective of the LWRSP RPV task is to develop robust predictions of transition temperature shifts (TTS) at high fluence $(\phi t)$ to at least $10^{20} \mathrm{n} / \mathrm{cm}^{2}(>1 \mathrm{MeV})$ pertinent to plant operation of some pressurized water reactors (PWR) for 80 full power years. Correlations between the high flux test reactor results and low flux surveillance specimens must be established for proper RPV embrittlement predictions of the current nuclear power fleet. Additionally, a complete understanding of defect evolution for high nickel RPV steels is needed to characterize the embrittlement potential of Mn-Ni-enriched precipitates (MNPs), particularly for the high fluence regime. While understanding of copper-enriched precipitates (CRPs) have been fully developed, the discovery and experimental verification [e.g., 5] of 'late blooming' MNPs in commercial reactor surveillance specimens with little to no copper for nucleation have stimulated research efforts to understand the evolution of these phases. New and existing databases will be combined to support development of physically based models of TTS for high fluence-low flux $\left(\phi<10^{11} \mathrm{n} / \mathrm{cm}^{2}-\mathrm{s}\right)$ conditions, beyond the existing surveillance database, to neutron fluences of at least $1 \times 10^{20} \mathrm{n} / \mathrm{cm}^{2}(>1$ $\mathrm{MeV})$. All references to neutron flux and fluence in this report are for fast neutrons $(>1 \mathrm{MeV})$.

The RPV task of the LWRS Program has worked with various organizations, including the Electric Power Research Institute (EPRI) and ATI-Consulting, to obtain archival surveillance materials from commercial nuclear power plants to allow for comparisons of the irradiation-induced microstructural features from reactor surveillance materials with those from similar materials irradiated under high flux conditions in test reactors, such as the UCSB ATR-2 experiment. EPRI is a participating collaborating organization in the ATR-2 experiment and shared in the funding directed at the testing of nine commercial reactor surveillance materials irradiated in the ATR-2 experiment. This report is focused on results of microhardness, shear punch, and tensile tests performed at ORNL and at UCSB. Much of the text in the following sections is gleaned from a previous progress report [6] and is repeated here for the convenience of the reader. As stated earlier, the primary goal of this work is to develop low flux embrittlement models beyond the fluence range available in the existing surveillance database. The ATR-2 experiment attained a high fluence, but at a higher flux than representative of commercial RPV surveillance programs. For this report the possible flux effects are not considered, but this is a large focus of future work. 


\section{BACKGROUND AND REVIEW OF UCSB ATR-2 EXPERIMENT}

To obtain high fluence data in a reasonable time (e.g., one or two years), test reactor experiments must be performed in such a way to enable development of a mechanistic understanding of the effects of flux [3,4]. As described previously, such an irradiation experiment has been performed as part of the Idaho National Laboratory (INL) Advanced Test Reactor (ATR) National Scientific User Facility (NSUF). The experiment was awarded to University of California, Santa Barbara (UCSB) and its collaborator, ORNL, several years ago with full funding for the irradiation experiment in the ATR provided by DOE through the NSUF. A detailed description of the UCSB ATR-2 experiment and materials provided in previous progress reports $[6,7,8]$ was also summarized in [9], and is summarized in sections 2 and 3 of this report.

In collaboration with UCSB, the INL staff carried out conceptual design of the sophisticated instrumented irradiation test assembly (capsule). The INL staff carried out the engineering design, construction and insertion of the test assembly, and was responsible for operation of the UCSB ATR2 irradiation experiment. The scientific experiment itself was designed by UCSB in collaboration with ORNL. The total of 173 alloys included in the experiment were acquired by UCSB and ORNL, including those contributed by Rolls Royce Marine (UK), Bettis Atomic Power Laboratory (US), and the Central Research Institute for the Electric Power Industry (Japan). Notably, the Rolls Royce contribution included a total of more than 50 new alloys. Additionally, surveillance materials from various operating nuclear reactors were obtained from U.S. Nuclear Industry organizations with the assistance of Mr. William Server of ATI-Consulting and are included to enable a direct comparison of results from a test reactor at high flux and a power reactor at low flux. The specific surveillance materials were described in detail in $[6,7,8]$ and are summarized in Section 3 of this report. Fabrication of the specimens was primarily carried out by UCSB with the assistance of ORNL. The specimens were loaded into 13 thin walled cups (cylindrical tubes) at UCSB and the cups were loaded into the test assembly at INL.

The irradiation was carried out in the so-called "Small I" position in ATR just inside the pressure vessel and reflector. The test assembly had a $20 \mathrm{~mm}$ inside diameter and was $\approx 1.2 \mathrm{~m}$ long. The UCSB ATR-2 experiment includes 1664 small specimens in three basic geometries. These include (1) tensile specimens, for a large matrix of alloys; (2) so-called multipurpose disc coupons (MPC) that will support microhardness, shear punch and a wide variety of microstructural characterization studies (e.g., small-angle neutron scattering, atom probe, small-angle x-ray scattering, etc.) for all the alloys; (3) 20-mm diameter disc compact tension (DCT) fracture specimens for three alloys - the Palisades B weld and two UCSB forgings (C17 and LP). The test assembly included a gadolinium thermal neutron shield and active temperature control with three major regions at nominal temperatures of 270,290 and $310^{\circ} \mathrm{C}$, and one small region at $250^{\circ} \mathrm{C}$. The gadolinium shield was incorporated to minimize activities of the specimens for post-irradiation examination (PIE). The specimens were irradiated at a peak flux of about $3.3 \times 10^{12} \mathrm{n} / \mathrm{cm}^{2}-\mathrm{s}(>1 \mathrm{MeV})$ to a target fluence of $1 \times 10^{20} \mathrm{n} / \mathrm{cm}^{2}$. The UCSB ATR-2 experiment reached a peak fluence of $\approx 1.4 \times 10^{20} \mathrm{n} / \mathrm{cm}^{2}$, which is about $60 \%$ larger than what some RPVs will reach at an 80 -year extended life. In addition, four capsules reached a peak fluence ranging from $5.1 \times 10^{19}$ to $9.1 \times 10^{19} \mathrm{n} / \mathrm{cm}^{2}$. These capsules will be used to directly compare data from this experiment to the lower fluence data available in surveillance programs. The identification, general specimen types, target irradiation temperature, and nominal target fluence ( $\phi \mathrm{t})$ for each of the 13 cups included in the ATR-2 capsule were provided in [10], while the average flux, fluence and irradiation temperature (target and as run) [11, 12] for each cup are given in Table 2.1. Except for the two bottom and two top cups, the as-run temperatures were very close to their target values. Details regarding determining the flux and temperature profiles in ATR-2 can be found in the INL as-run reports [11, 12]. 
ORNL/TM-2017/172

Table 2.1 Neutron flux, fluence $(E>1 \mathrm{MeV})$ and temperature for the various cups in the ATR-2 irradiation.

\begin{tabular}{ccccc}
\hline Cup & Flux $\left(10^{12} \mathrm{n} / \mathrm{cm}^{2}-\mathrm{s}\right)$ & Fluence $\left(10^{19} \mathrm{n} / \mathrm{cm}^{2}\right)$ & Target $\mathrm{T}_{\text {irr }}\left({ }^{\circ} \mathrm{C}\right)$ & Actual $\mathrm{T}_{\text {irr }}\left({ }^{\circ} \mathrm{C}\right)$ \\
\hline 1 & 1.34 & 5.11 & 290 & 247 \\
2 & 1.94 & 7.43 & 290 & 268 \\
3 & 2.54 & 10.35 & 290 & 280 \\
4 & 3.13 & 11.90 & 270 & 268 \\
5 & 3.36 & 12.80 & 250 & 255 \\
6 & 3.58 & 13.70 & 290 & 285 \\
7 & 3.64 & 13.90 & 290 & 291 \\
8 & 3.60 & 13.70 & 290 & 293 \\
9 & 3.47 & 13.20 & 290 & 293 \\
10 & 3.21 & 12.30 & 310 & 319 \\
11 & 2.89 & 11.05 & 290 & 292 \\
12 & 2.17 & 9.08 & 290 & 264 \\
13 & 1.52 & 5.79 & 290 & 238 \\
\hline
\end{tabular}

\section{DESCRIPTION OF MATERIALS AND SPECIMENS}

A summary of the materials, specimen types and numbers is provided in Table 3.1, while the materials are described in greater detail in [9]. As mentioned earlier, 173 alloys with 1664 specimens were included in the capsule. The DCT matrix includes three alloys, the Palisades B weld and two UCSB forgings (C17 and LP), while the UCSB commercial alloys include HSST Plate 02, HSSI Weld 73W, Midland Beltline Weld (WF-70), and other alloys from the UCSB IVAR project, etc. The group designated EPRI alloys are various RPV materials irradiated and examined in previous experiments for EPRI by UCSB. From a large group of materials identified as potential candidates, and with the major assistance of ATI-Consulting, we procured nine specific RPV surveillance materials from various operating nuclear reactors for inclusion in the ATR-2 capsule; they are designated ORNL alloys and are shown in Table 3.2 (the Material Codes shown are specific to this report to replace the nuclear plant name with which the material is associated, and for ease of discussion). These nine materials were identified as those that would provide results of particular interest to the ATR-2 experimental objectives. Additionally, they were identified based not only on their chemical composition but also on their inclusion in commercial RPV surveillance capsules intended for relatively high fluence to allow for comparisons of results from surveillance conditions and the test reactor conditions in the ATR-2 and subsequent experiments. The chemical compositions of the nine surveillance materials are provided in Table 3.3, while Figure 3.1 provides a graphical comparison of the copper, nickel, manganese, and silicon contents, indicating a wide range of those four elements that are major contributors to irradiation-induced embrittlement. The copper range is 0.03 to $0.36 \mathrm{wt} \%$, nickel range is 0.19 to $0.90 \mathrm{wt} \%$, manganese range is 0.79 to $1.44 \mathrm{wt} \%$, and silicon range is 0.18 to $0.45 \mathrm{wt} \%$. Compositions for each material were taken from the Reactor Embrittlement Archive Project (REAP) [13], sponsored by the USNRC at ORNL, which gleaned the information from the appropriate commercial reactor surveillance reports available in the USNRC database.

More detailed lists of alloys and specimens are shown in Appendix A and Appendix B of [9], with Appendix B indicating the target irradiation temperatures for the various alloys and specimens. Additionally, Appendix C of [9] contains individual tables for the various groups of materials for easier reference by the material group. In summary, a variety of relatively small specimens of many 
ORNL/TM-2017/172

different RPV steels have been irradiated in UCSB ATR-2, including many materials that have been irradiated and tested in previous test reactors and surveillance programs at different flux levels.

Table 3. 1 Specimen Matrices Summary for ATR-2 Experiment.

\begin{tabular}{|l|c|c|c|c|c|c|c|c|c|c|}
\hline & \multicolumn{2}{|c|}{ Lg Disc } & \multicolumn{2}{c|}{ Sm Disc } & \multicolumn{2}{c|}{ Tens } & \multicolumn{2}{c|}{ DCT } & \multicolumn{2}{c|}{ Any Type } \\
\hline \multicolumn{1}{|c|}{ Total\# alloy/irrad cond } & Alloy & Spc. & Alloy & Spc. & Alloy & Spc. & Alloy & Spc. & Alloy & Spc. \\
\hline \multicolumn{1}{|c|}{ Total \# spc } & 144 & 1028 & 40 & 224 & 55 & 367 & 3 & 45 & 173 & 1664 \\
\hline DCT matrix & 3 & 14 & & & 3 & 54 & 3 & 45 & 3 & 113 \\
\hline CM alloys & 21 & 231 & & & 13 & 92 & & & 21 & 323 \\
\hline Laval alloys & 10 & 72 & & & 8 & 48 & & & 10 & 120 \\
\hline UCSB Commercial alloys & 13 & 107 & 1 & 4 & 9 & 53 & & & 13 & 164 \\
\hline EPRI alloys & 20 & 141 & & & 6 & 21 & & & 20 & 162 \\
\hline ORNL alloys & 5 & 64 & 5 & 41 & 8 & 51 & & & 9 & 156 \\
\hline RR alloys & 57 & 356 & 11 & 80 & 8 & 48 & & & 68 & 484 \\
\hline Bettis alloys & 5 & 25 & & & & & & & 5 & 25 \\
\hline CRIEPI alloys & & & 13 & 65 & & & & & 13 & 65 \\
\hline OV model alloys & 9 & 15 & 10 & 34 & & & & & 10 & 49 \\
\hline Diffusion Multiples & 1 & 3 & & & & & & & 1 & 3 \\
\hline
\end{tabular}

Table 3.2. List of archival commercial reactor surveillance materials.

\begin{tabular}{|c|c|c|c|}
\hline Material Code & Material & Heat Number & Specimen Provided \\
\hline $\mathrm{A}$ & Weld & $33 \mathrm{~A} 277$ & \\
\hline B & Plate SA533B-1 & C7466-1 & $\begin{array}{c}\text { Two (2) 1/2T-CT } \\
\text { "CT29" and "CL28"(a) }\end{array}$ \\
\hline $\mathrm{C}$ & Forging, SA 508-2 & 123X167VA1 & $\begin{array}{c}\text { Block } 3.19 \times 0.875 \times 0.55 \\
\text { in. }\end{array}$ \\
\hline $\mathrm{D}$ & Linde 1092 Weld-M & 1P3571 & $\begin{array}{c}\text { Two (2) untested tensile } \\
\text { "4KL" and "3J2" } \\
\text { Two (2) broken Charpy } \\
\text { halves from specimen } \\
\text { "372" }\end{array}$ \\
\hline $\mathrm{E}$ & Plate SA533B-1 & $\begin{array}{l}\text { Heat C0544-2 } \\
\text { Plate B9004-2 }\end{array}$ & Block $5 \times 2.25 \times 2.375$ in. \\
\hline $\mathrm{F}$ & Linde 1092 Weld-K & 1P3571 & $\begin{array}{l}0.5 " \times 3 " x 1.5 " \text { slice of } \\
\text { weldment (weld marked) }\end{array}$ \\
\hline $\mathrm{G}$ & SMAW & BOLA & $\begin{array}{c}\text { One (1) 1/2T-CT } \\
\text { "CW25" }\end{array}$ \\
\hline $\mathrm{H}$ & Linde 124 Weld & $4 \mathrm{P} 4784$ & $\begin{array}{c}\text { One (1) 1/2T-CT } \\
\text { "CW26" }\end{array}$ \\
\hline I & $\begin{array}{c}\text { Linde } 80 \text { Weld, SA- } \\
1094\end{array}$ & $\begin{array}{l}\text { Weld wire heat } \# 71249 \text { and } \\
\text { Linde } 80 \text { flux lot } 8457 .\end{array}$ & $\begin{array}{c}\text { Block } 3.375 \times 4.25 \times 8.625 \\
\text { in. (Block returned } \\
\text { following machining of } \\
\text { specimens) }\end{array}$ \\
\hline
\end{tabular}

Notes: "(a) "CT" refers to transverse orientation and "CL" refers to longitudinal orientation. 
ORNL/TM-2017/172

Table 3.3. Chemical composition of archival commercial reactor surveillance materials.

\begin{tabular}{|c|c|c|c|c|c|c|c|c|c|}
\hline & \multicolumn{7}{|c|}{ Chemical Composition, wt } \\
\hline Material Code & $\mathrm{Cu}$ & $\mathrm{Ni}$ & $\mathrm{Mn}$ & $\mathrm{Si}$ & $\mathrm{Cr}$ & $\mathrm{Mo}$ & $\mathrm{P}$ & $\mathrm{C}$ & $\mathrm{S}$ \\
\hline $\mathrm{A}$ & 0.14 & 0.19 & 1.06 & 0.27 & 0.06 & 0.50 & 0.016 & 0.13 & 0.009 \\
\hline B & 0.20 & 0.60 & 1.33 & 0.23 & 0.11 & 0.49 & 0.005 & 0.22 & 0.016 \\
\hline $\mathrm{C}$ & 0.06 & 0.75 & 0.79 & 0.28 & 0.35 & 0.58 & 0.010 & 0.20 & 0.009 \\
\hline $\mathrm{D}$ & 0.36 & 0.78 & 1.42 & 0.18 & 0.04 & 0.49 & 0.013 & 0.18 & 0.011 \\
\hline E & 0.05 & 0.56 & 1.32 & 0.24 & 0.08 & 0.59 & 0.010 & 0.24 & 0.016 \\
\hline F & 0.22 & 0.72 & 1.37 & 0.20 & 0.09 & 0.48 & 0.016 & 0.12 & 0.011 \\
\hline G & 0.03 & 0.90 & 0.94 & 0.32 & 0.03 & 0.23 & 0.004 & 0.14 & 0.014 \\
\hline H & 0.04 & 0.95 & 1.41 & 0.45 & 0.13 & 0.48 & 0.009 & 0.09 & 0.009 \\
\hline I & 0.29 & 0.60 & 1.44 & 0.50 & 0.14 & 0.36 & 0.014 & 0.10 & 0.011 \\
\hline
\end{tabular}

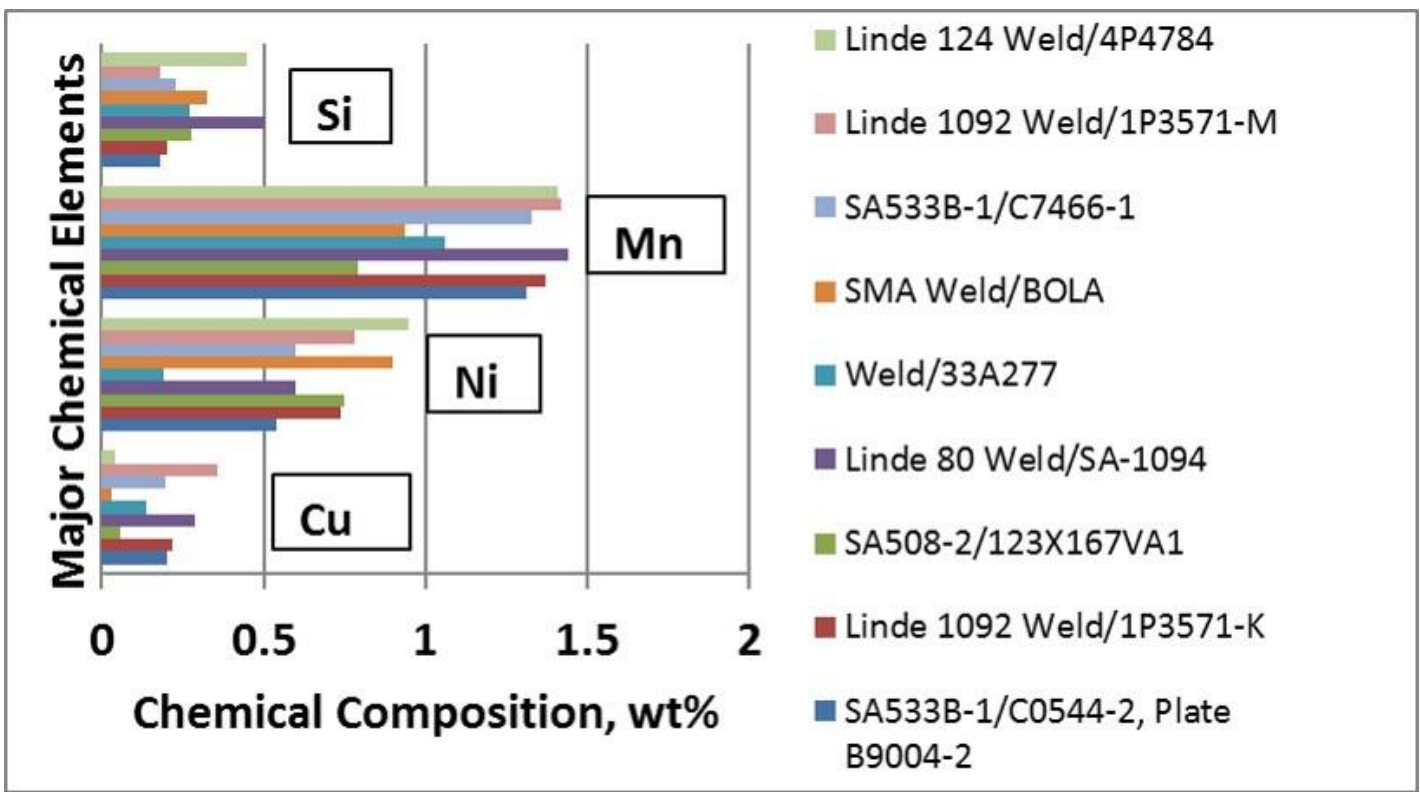

Figure 3.1. Content of major irradiation-sensitive chemical elements for nine commercial reactor surveillance materials in the UCSB ATR-2 experiment.

Specimens of the surveillance materials shown in Tables 3.2 and 3.3 and discussed in this report were irradiated in Cup 7 to an average fluence of $1.39 \times 10^{20} \mathrm{n} / \mathrm{cm}^{2}$ at an average temperature of $291^{\circ} \mathrm{C}$, as shown in Table 2.1. Tensile specimens are tested in accordance with ASTM Standard Test Procedure E8 to obtain yield and ultimate strengths for comparison with those of the unirradiated 
ORNL/TM-2017/172

condition and with the microhardness (tested in accordance with ASTM Standard Test Method for Microindentation Hardness of Materials E384-16, with some high load tests (10-kg load) performed in accordance with ASTM E92-16, Standard Test Methods for Vickers Hardness and Knoop Hardness of Metallic Materials) and shear punch results. Those results will be correlated to ascertain the effects of irradiation on hardening. Figure 3.2 shows a schematic diagram of the 20 -mm multipurpose disc while Figure 3.3 shows a diagram of the loading scheme for the $8-\mathrm{mm}$ discs in a 20-mm diameter container. Figure 3.4 shows a similar schematic diagram for the tensile specimens and the loading scheme. Figure 3.5 shows a schematic diagram of the single specimen shear punch tester at UCSB, while the excellent correlation between tensile specimen yield strength and shear punch strength measurements from [14] are shown graphically in Figure 3.6 for the unirradiated materials. For the irradiated specimens, a correlation constant of 1.89 was determined.

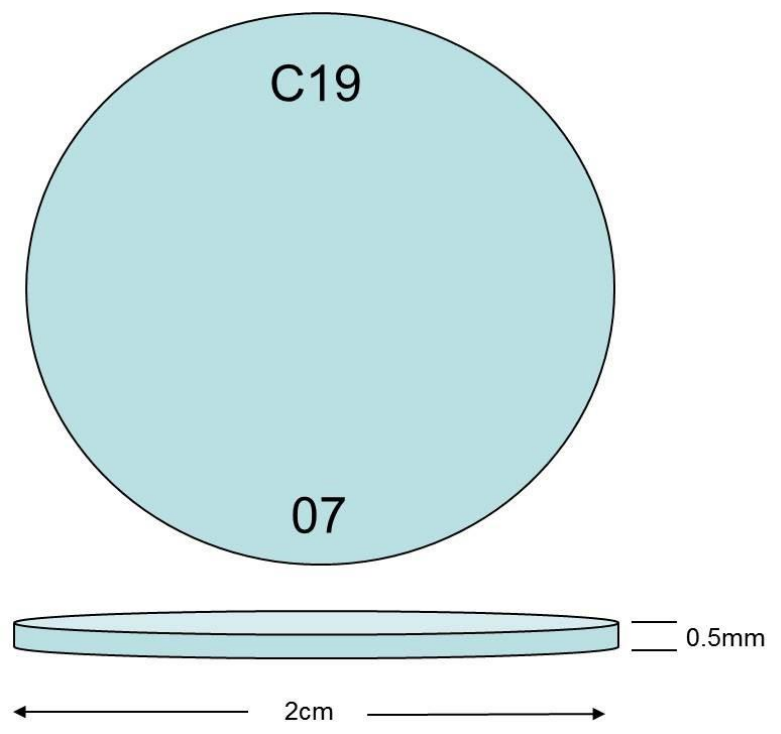

Figure 3.2. Schematic diagram of the multi-purpose disc specimen with diameter and thickness indicated.

Small (8mm dia.) discs:

three stacks of 10 pressed into holder

Figure 3.3. Schematic diagram showing the concept for loading of 8-mm multi-purpose disc specimens into the sub-capsule holders. 


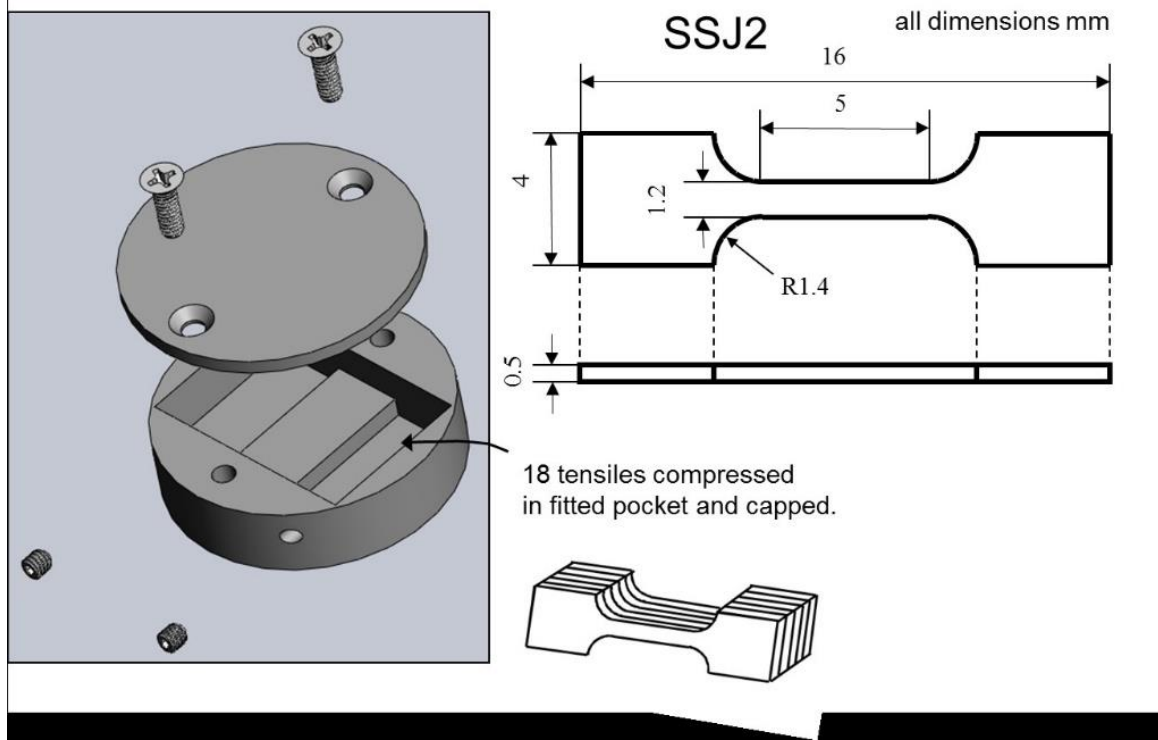

Figure 3.4. Schematic of the tensile loading box (left) and SSJ-2 tensile specimens (right). Note that half of the specimens have a gauge length of $5.00 \mathrm{~mm}$ (showed), while the others have a 2.2 mm gauge length.

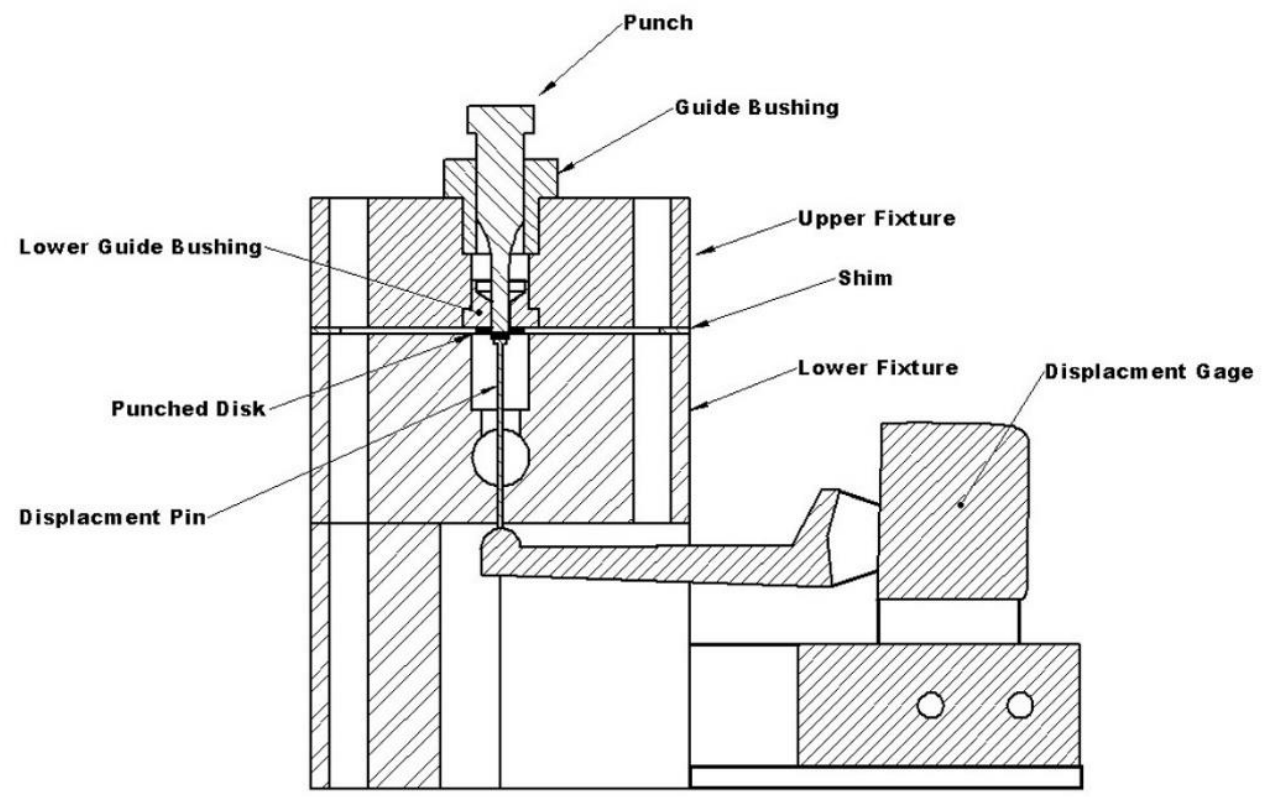

Figure 3.5. Schematic of the single specimen punch shear punch tester at UCSB. 


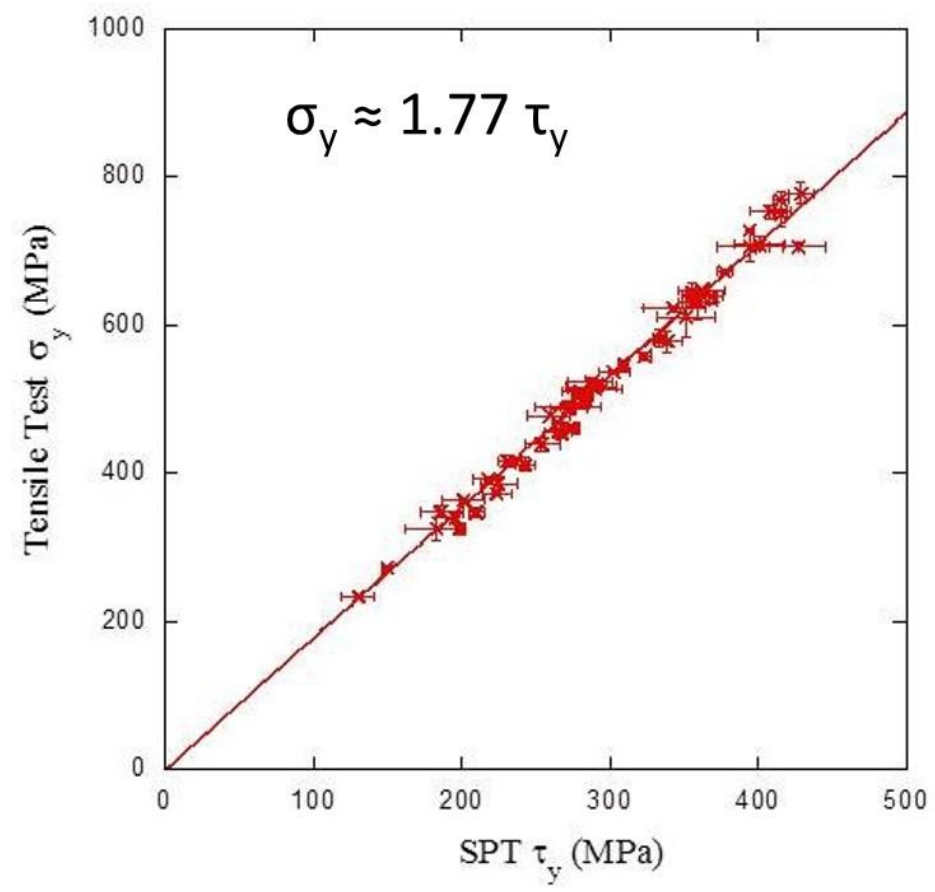

Figure 3.6. Yield strength from tensile specimens $\left(\sigma_{y}\right)$ vs shear punch $\left(\tau_{y}\right)$ tests indicating an excellent correlation for steels with a wide range of yield strengths showing the empirical relation $\sigma_{\mathrm{y}} \approx 1.77 \tau_{\mathrm{y}}$.

\section{THE ATR-2 EXPERIMENT CAPSULE DISASSEMBLY}

Fabrication and assembly of the UCSB ATR-2 irradiation test assembly was completed in late spring of 2011 and was successfully installed in the ATR on May 26, 2011. The irradiation began on June 7, 2011 and was anticipated to achieve its target fluence of $1 \times 10^{20} \mathrm{n} / \mathrm{cm}^{2}(\mathrm{E}>1 \mathrm{MeV})$ in the autumn of 2012. A number of delays in operation of the ATR pushed the completion of the ATR-2 irradiation campaign to January of 2014 following completion of cycle $155 \mathrm{~A}$. Chief among these was the Powered Axial Locator Mechanism (PALM) cycle. The irradiation (ATR cycle 155A) was completed on 17 January 2014 with peak and average fluences of 1.4 and $1.0 \times 10^{20} \mathrm{n} / \mathrm{cm}^{2}(\mathrm{E}>1 \mathrm{MeV})$, respectively, which met the objective of reaching a fast fluence of at least $0.90 \times 10^{20} \mathrm{n} / \mathrm{cm}^{2}$. Following completion of the irradiation campaign, the ATR-2 capsule was stored in the ATR canal until ready for disassembly operations. In June of 2014, the experiment was cropped in the canal. A dry cap was installed and the experiment passed the 30-psi pressure test, while the bails on the capsule were successfully removed with an underwater saw specifically designed and fabricated for that purpose. In July, the experiment was moved into a cask suitable for internal transfers within INL, and in August the experiment was moved into the Dry Transfer Cubicle (DTC) for final sizing. In early October of 2014, the experiment was sized in the DTC following significant difficulty with cutting through some of the irradiation-hardened capsule material and then sent to the INL Materials and Fuels Complex (MFC) for subsequent disassembly to remove the 13 cups that contain the test specimens.

The original concept of opening the ends of the capsule and pushing the 13 cups out of the capsule was met with great difficulty and was eventually abandoned in favor of using a mill to cut the capsule open longitudinally and removing the cups by prying open the capsule. This difficult operation was completed in mid-June of 2015 with some of the very thin-wall cups cut open by the mill cutter. It appears at this time, however, that there was no damage that would compromise the 
utility of the specimens. Following the disassembly operation described above, the specimen cups were loaded into transport pigs, placed in three shielded drums, and shipped to ORNL, where they were received on 10 July 2015 at the Irradiated Materials Examination and Testing (IMET) hot cell facility.

\section{POST-IRRADIATION EXAMINATION OF NINE ARCHIVAL SURVEILLANCE MATERIALS}

\subsection{Post-Irradiation Examination Plan}

The PIE plan for examination of the ATR-2 experiment is considered to be fluid and flexible to accommodate changing emphasis on results in order to meet project objectives. It was also not known with certainty that the radioactivity of the samples would allow for most of them to be tested in the ORNL Low Activated Materials Development and Analysis (LAMDA) laboratory and at UCSB. Activity measurements performed on selected specimens from cup 7 at the ORNL IMET hot cells confirmed that the activities of the specimens indicate that most have sufficiently low activity to enable testing in those low activity laboratories. The general steps for the PIE evaluation and priorities are discussed in detail in [6,9], but the top two priorities were a series of UCSB alloys irradiated in multiple previous experiments and the ORNL surveillance materials irradiated at a target temperature of $290^{\circ} \mathrm{C}$ in Cup 7.

The statement of work for the subcontract with EPRI provides for microhardness, shear punch, and tensile tests to be performed at room temperature with the appropriate irradiated large discs, small discs, or tensile specimens for each of the nine surveillance materials, to include a similar number of tests with unirradiated specimens of the same materials. Beyond the specific testing performed for EPRI, additional microstructural investigations, such as atom probe tomography, small-angle neutron scattering, transmission electron microscopy, and small-angle X-ray scattering, are tentatively planned for these and many other materials included in the ATR-2 experiment and will be reported separately. Some results and information in the following sections have been gleaned with permission from a progress report by UCSB [15].

\subsection{Tensile and Microhardness Test Results}

For the surveillance material test project, all tensile tests, unirradiated and irradiated, were performed by UCSB [15] with the specimen types shown in Fig. 3.4; no significant differences in the tensile properties have been observed between the two gauge lengths. Three or more unirradiated (control) specimens were tested to establish the baseline yield stress $\left(\sigma_{\mathrm{y}}\right)$ and ultimate engineering tensile stress $\left(\mathrm{s}_{\mathrm{u}}\right)$, and used to determine the corresponding irradiation hardening $\left(\Delta \sigma_{\mathrm{y}}\right.$ and $\left.\Delta \mathrm{s}_{\mathrm{u}}\right)$. As stated in [15]: "The dog-bone tensile specimens are clamped by grips in an alignment fixture prior to placement in on an MTS 810 load frame. The specimens were loaded at a rate of $0.008 \mathrm{~mm} / \mathrm{s}$ at strain rates of 0.002 to $0.003 / \mathrm{min}$. Standard engineering stress-strain curves are recorded based on precise measurements of the width and thickness of the gauge section of individual specimens. A best fit to the elastic loading region is used to establish the $0.2 \%$ offset yield stress $\left(\sigma_{\mathrm{y}} \approx \mathrm{s}_{\mathrm{y}}\right)$. The ultimate engineering stress $\left(\mathrm{s}_{\mathrm{u}}\right)$ at maximum load is also recorded. The tensile tests on irradiated specimens are generally stopped at a load that is $\approx 70 \%$ of the maximum to keep the specimen intact." An example stress-strain curve, with a $0.2 \%$ offset line is shown in Figure 5.1.

Multiple hardness tests were performed in the ORNL LAMDA laboratory and at UCSB in accordance with the appropriate ASTM standards stated in Section 3 above. A Wilson microhardness tester was used at ORNL to make 5 indents per specimen. Initial tests at ORNL were performed with 10 -kg loads on unpolished 20 - $\mathrm{mm}$ and 8 - $\mathrm{mm}$ discs while subsequent tests were performed with 0.5 $\mathrm{kg}$ loads on polished 3-mm discs that had been punched from larger discs using the UCSB designed and provided punching device that allows punching of 3-mm diameter discs with retention of disc flatness. The designation of ORNL_NA refers to results determined in the ORNL LAMDA laboratory 
ORNL/TM-2017/172

by a visiting UCSB student, Nathan Almirall. Microhardness tests on the same materials in the unirradiated condition were also performed at UCSB using the same procedure; the ORNL and UCSB results agreed within less than $\pm 2 \%$ for all nine materials, providing confidence that results from those two laboratories can be combined for unirradiated and irradiated testing. In both laboratories, standard calibration blocks were used to ensure accuracy of the hardness test machines. The $0.5-\mathrm{kg}$ load procedure with polished specimens is the procedure used by UCSB for many years to establish correlations between microhardness and tensile yield strength for a wide variety of RPV steels and weld metals. Thus, the microhardness results in this report will be focused on the $0.5-\mathrm{kg}$ data for correlation with irradiation-induced tensile yield strength changes, which are subsequently used for predictions of Charpy impact 41-J shifts. For research purposes, the LWRS Program will continue to evaluate the procedure using a $10-\mathrm{kg}$ load with unpolished specimens as a potential alternative.

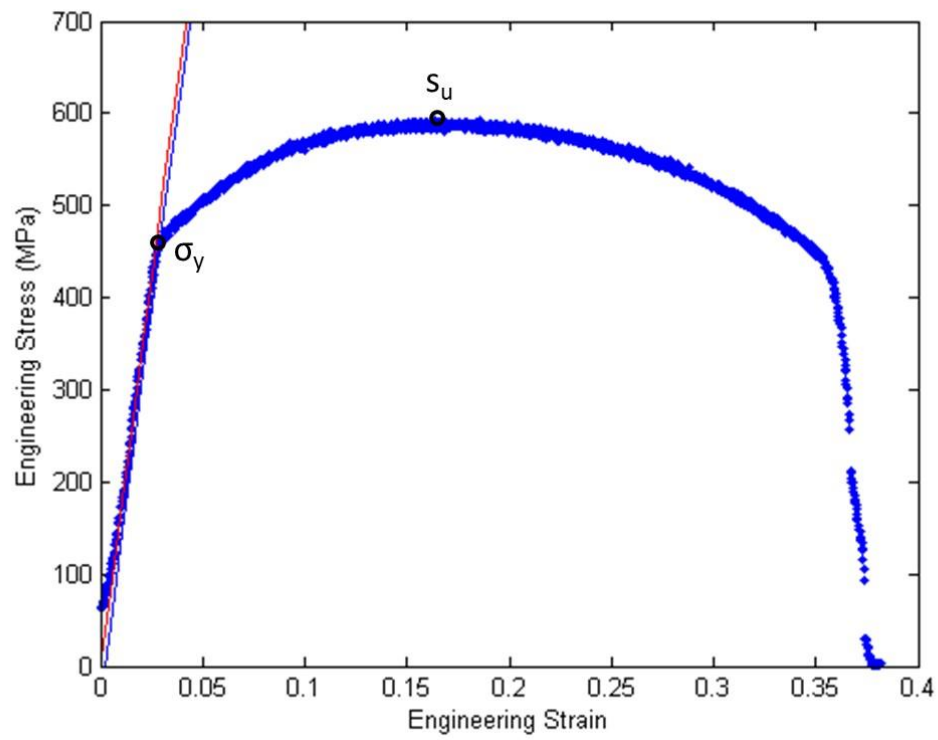

Figure 5.1. Example stress-strain curve with $0.2 \%$ offset line.

Table 5.1 provides the results of microhardness testing for both the $10-\mathrm{kg}$ and $0.5-\mathrm{kg}$ procedures at ORNL as well as the microhardness-based predicted yield strength changes for each case. To obtain the predicted yield strength change, the microhardness change is multiplied by 3.33 as developed over many years of such testing by UCSB $[14,15]$. A fit to a wide range of steels tested for the ATR-2 project and the specific subset of surveillance materials resulted in coefficients of 3.4 and 3.23 , respectively, indicating that the use of the 3.33 value from a much larger database is reasonable for this application. Figure 5.2 shows the comparison for the surveillance materials [15]. The table also provides the measured irradiated-induced yield strength changes determined by UCSB. The farright column shows that the microhardness predicted yield strength changes are within $\pm 25 \%$ except for the Material G. Material D is shown as ND due to an apparent faulty tensile test which indicated an abnormally low yield strength; additional testing will be performed. 
ORNL/TM-2017/172

Table 5.1. Summary of microhardness testing for nine RPV surveillance materials.

\begin{tabular}{|c|l|l|l|l|l|c|}
\hline & \multicolumn{2}{|c|}{$\begin{array}{c}\text { Hv 10kg } \\
\text { ORNL }\end{array}$} & \multicolumn{3}{c|}{$\begin{array}{c}\text { Hv 0.5kg } \\
\text { ORNL_NA }\end{array}$} & $\begin{array}{l}\text { Tensiles } \\
\text { UCSB }\end{array}$ \\
\hline Material Code & $\begin{array}{l}\Delta \mathbf{H v} \\
(\text { VH) }\end{array}$ & $\Delta \sigma_{\mathbf{y}}$ (MPa) & $\Delta$ Hv (VH) & $\Delta \sigma_{\mathbf{y}}$ (MPa) & $\begin{array}{l}\Delta \sigma_{\mathbf{y}} \\
(\text { MPa) }\end{array}$ & $\begin{array}{c}\text { Ratio of } \\
\text { Tensile } \Delta \sigma_{\mathbf{y}} \text { to } \\
\text { Hv 0.5kg } \Delta \sigma_{\mathbf{y}}\end{array}$ \\
\hline A & 46.6 & 155.2 & 53.9 & 179.5 & 165.0 & 0.92 \\
\hline B & 66.2 & 220.4 & 78.7 & 262.1 & 244.0 & 0.93 \\
\hline C & 56.0 & 186.5 & 47.9 & 159.5 & 178.0 & 1.12 \\
\hline D & 109.0 & 363.0 & 88.5 & 294.7 & ND* & ND* \\
\hline E & 43.2 & 143.9 & 41.3 & 137.7 & 151.0 & 1.10 \\
\hline F & 104.0 & 346.3 & 109.1 & 363.3 & 291.0 & 0.80 \\
\hline G & 64.0 & 213.1 & 64.1 & 213.3 & 145.0 & 0.68 \\
\hline H & 66.4 & 221.1 & 49.3 & 164.2 & 206.0 & 1.25 \\
\hline I & 88.4 & 294.4 & 91.7 & 305.3 & 271.0 & 0.89 \\
\hline
\end{tabular}

*ND: Not determined due to a faulty tensile test; the material will be retested.

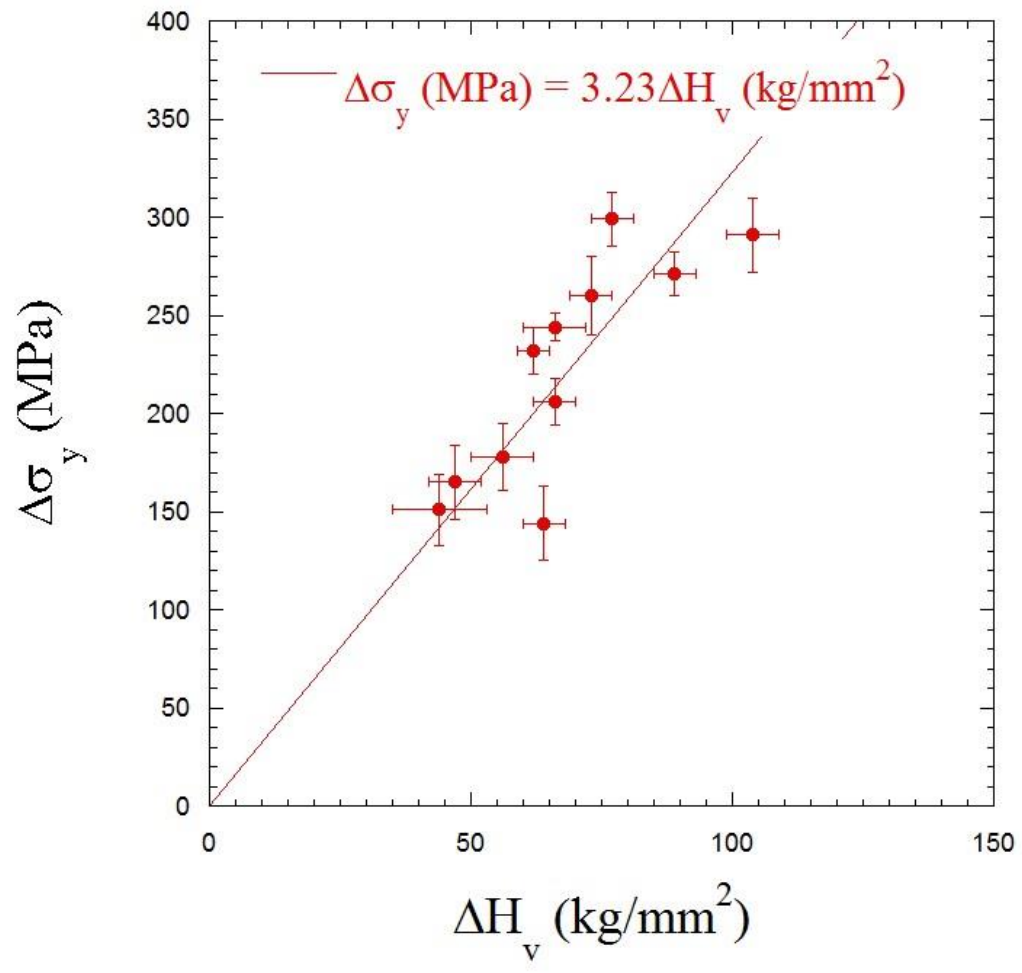

Figure 5.2. Change in tensile yield stress versus change in microhardness for a subset of surveillance alloys in cup 7 [15].

\subsection{Shear Punch Test Results}

The load-displacement data from shear punch tests (SPT) can be used to derive true-stress, true-strain $(\sigma-\varepsilon)$ data. However, the SPT performed by UCSB for this work was used to measure the shear yield stress $\left(\tau_{\mathrm{y}}\right)$ and its relation to the tensile yield strength $\left(\sigma_{\mathrm{y}}\right)$. A detailed description of the SPT is provided in [14], but the shear stress is calculated based on punch load (P), the average of the punch and die diameter (D), and specimen thickness (t) as $\tau=P /(\pi D t)$. The shear strain $\left(e_{s}\right)$ is defined 
by dividing the measured backside displacement by the multi-purpose disc thickness. Thus, the measured load and displacement can be converted to shear stress and strain. A typical shear punch curve is shown in Figure $5.3[14,15]$.

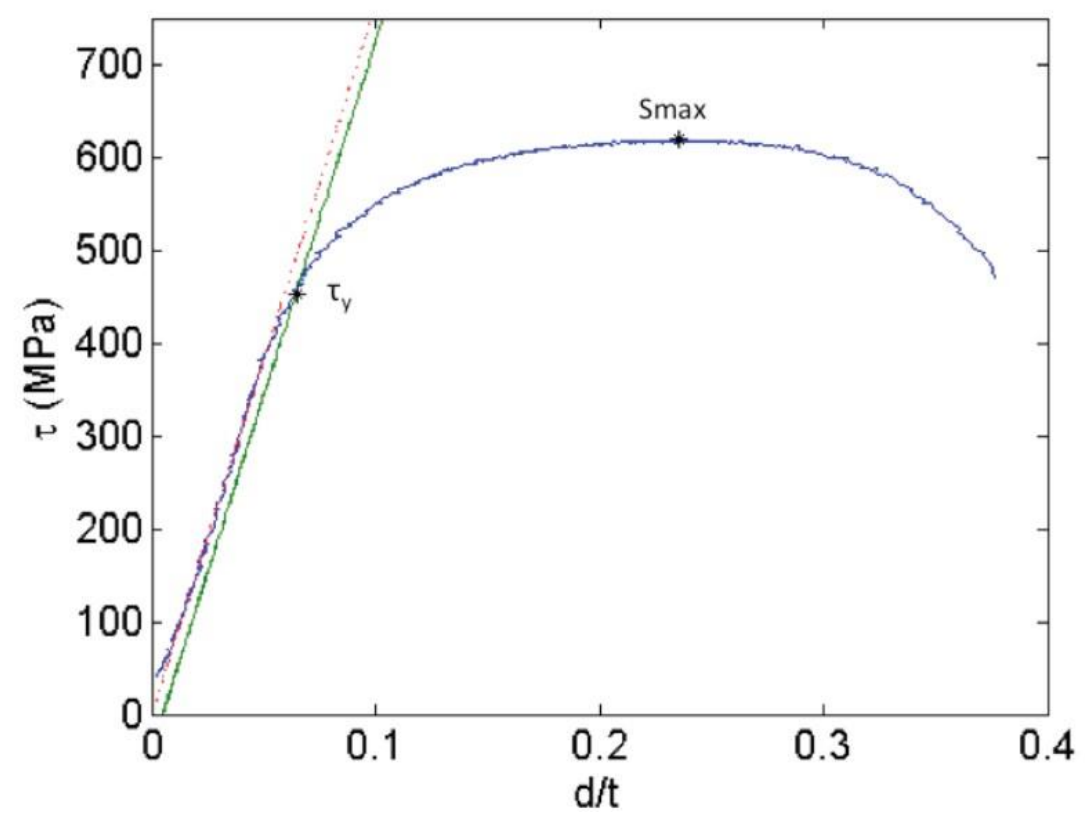

Figure 5.3. A typical shear punch curve $[14,15]$.

A previously established relation, of $\sigma_{\mathrm{y}} \approx 1.77 \tau_{\mathrm{y}}$, is close to the theoretical Von Mises value of $\sqrt{3}[9,14,15]$. Shear punch testing of unirradiated and irradiated $20-\mathrm{mm}$ discs of the nine surveillance materials was performed at UCSB using the single specimen shear punch device shown in Fig. 3.5. Table 5.2 provides a summary of the results, including the predicted material tensile yield strength $\left(\sigma_{\mathrm{y}}\right)$ from the shear strength $\left(\tau_{\mathrm{y}}\right)$ using the correlation $\sigma_{\mathrm{y}}=\mathrm{C} \tau_{\mathrm{y}}$, where $\mathrm{C}$ is 1.77 for the unirradiated specimens and 1.89 for the irradiated specimens [15]. The far-right column shows that the shear punch predicted yield strength changes are within about $\pm 30 \%$ except for Material E plate and Material $\mathrm{C}$ forging. Combining the results of microhardness and shear punch testing relative to predictions of irradiation-induced changes in tensile yield strength, Table 5.3 compares the average of those two test predictions with the measured tensile results, showing the predictions are within about $\pm 30 \%$

Table 5.2. Summary of shear punch testing for nine RPV surveillance materials.

\begin{tabular}{|c|c|c|c|c|c|}
\hline & \multicolumn{2}{|c|}{$\begin{array}{c}\text { Converted } \boldsymbol{\sigma}_{\mathbf{y}} \text { (MPa) (from } \\
\text { Shear Yield) }\end{array}$} & \multicolumn{2}{c|}{$\Delta \boldsymbol{\sigma}_{\mathbf{y}}$ (MPa) } & \\
\hline Material Code & Unirradiated & Irradiated & $\begin{array}{c}\text { Shear } \\
\text { Correlation }\end{array}$ & $\begin{array}{c}\text { Tensiles } \\
\text { UCSB }\end{array}$ & $\begin{array}{c}\Delta \boldsymbol{\sigma}_{\mathbf{y}} \text { Ratio } \\
\text { of Tensile } \\
\text { to Shear }\end{array}$ \\
\hline A & 469 & 602 & 132 & 165 & 1.25 \\
\hline B & 474 & 709 & 235 & 244 & 1.04 \\
\hline C & 514 & 628 & 114 & 178 & 1.56 \\
\hline D & 447 & 808 & 361 & ND* & ND* \\
\hline E & 521 & 621 & 100 & 151 & 1.51 \\
\hline F & 466 & 757 & 292 & 291 & 1.00 \\
\hline G & 445 & 655 & 210 & 145 & 0.69 \\
\hline H & 449 & 682 & 233 & 206 & 0.88 \\
\hline I & 468 & 727 & 259 & 271 & 1.05 \\
\hline
\end{tabular}

*ND: Not determined due to a faulty tensile test; the material will be retested. 
Table 5.3. Summary of hardness and shear punch predictions of $\Delta \sigma_{y}$

\begin{tabular}{|c|c|c|c|c|c|}
\hline Material Code & $\begin{array}{c}\text { Tensile } \\
\Delta \sigma_{\mathrm{y}}, \\
(\mathbf{M P a})\end{array}$ & $\begin{array}{c}\text { Hardness } \\
\text { Predicted } \\
\Delta \sigma_{\mathrm{y}}, \\
(\mathrm{MPa})\end{array}$ & $\begin{array}{c}\text { Shear } \\
\text { Punch } \\
\text { Predicted } \\
\Delta \sigma_{y},(\text { MPa) }\end{array}$ & $\begin{array}{c}\text { Average of } \\
\text { Hardness \& } \\
\text { SPT Predicted } \\
\Delta \sigma_{\mathrm{y}},(\mathrm{MPa})\end{array}$ & $\begin{array}{c}\Delta \sigma_{\mathrm{y}} \text { Ratio } \\
\text { Tensile to } \\
\text { Average } \\
\text { Predictions }\end{array}$ \\
\hline $\mathrm{A}$ & 165 & 180 & 132 & 156 & 1.06 \\
\hline B & 244 & 262 & 235 & 249 & 0.98 \\
\hline $\mathrm{C}$ & 178 & 160 & 114 & 137 & 1.30 \\
\hline $\mathrm{D}$ & ND* & 295 & 361 & 328 & ND* \\
\hline $\mathrm{E}$ & 151 & 138 & 100 & 119 & 1.27 \\
\hline $\mathrm{F}$ & 291 & 363 & 292 & 328 & 0.89 \\
\hline $\mathrm{G}$ & 145 & 213 & 210 & 212 & 0.68 \\
\hline $\mathrm{H}$ & 206 & 164 & 233 & 199 & 1.04 \\
\hline I & 271 & 305 & 259 & 282 & 0.96 \\
\hline
\end{tabular}

*ND: Not determined due to a faulty tensile test; the material will be retested.

\subsection{Comparison of Mechanical Property Results with Surveillance Data}

Given the objective to develop embrittlement predictive models at high fluence beyond that currently available for U.S. commercial RPV surveillance data, it is of interest to compare the hardening and embrittlement predictions based on the ATR-2 microhardness and shear punch test results with surveillance data for the same materials. As stated earlier, surveillance reports are available in the USNRC database and the data from those reports have been collected by the Reactor Embrittlement Archive Project (REAP) [13] sponsored by the USNRC at ORNL. The REAP database was used to obtain tensile and Charpy impact results for the nine surveillance materials with a few additional data gleaned from recent surveillance reports not yet imported into the REAP database. As with the prediction of tensile yield strength based on microhardness and SPT tests, prediction of the irradiation-induced Charpy impact 41-J shift based on the change in yield strength depends on developed correlations. In [16], Odette, et. al., analyzed an extensive database of surveillance data and developed correlations between the irradiation-induced yield strength increase and the Charpy impact 41-J shift, resulting in an overall relationship of $\Delta \mathrm{TT}_{41 \mathrm{~J}}=0.7^{*} \Delta \sigma_{\mathrm{y}}$. The original equations from [16] have been used to develop both power law and linear fits as shown in Figure 5.4 with separate equations for weld metals and base metals. The power law provides better fits than the linear case (intercept forced to zero), but the linear fits with coefficients of 0.724 and 0.672 show that the use of an overall coefficient of 0.7 is reasonable for these initial analyses, with two standard deviations of $\pm 16-20 \%$. Figures 5.5 (a) and (b) shows plots of surveillance data for the nine surveillance materials with the equations from Fig. 5.4 (b) and actual fits to the data for comparison, but the linear fits in these cases are not forced to zero. The fits from Fig. 5.4 (b) are better for the base metal data than for the weld metal data, but, given the relatively sparse number of data, the agreement in both cases is quite good, providing additional confidence that the overall relationship of $\Delta \mathrm{TT}_{41 \mathrm{~J}}=0.7 * \Delta \sigma_{\mathrm{y}}$ is reasonable for this current application. There are other published comparisons that provide similar values, such as [17]. It is recognized that such an average conversion factor may not be accurate for a specific RPV material. Given the substantially larger surveillance database currently available, a reevaluation of the relationship between tensile yield strength increases and Charpy impact shifts may result in more definitive correlations for welds and base metals. 
(a)

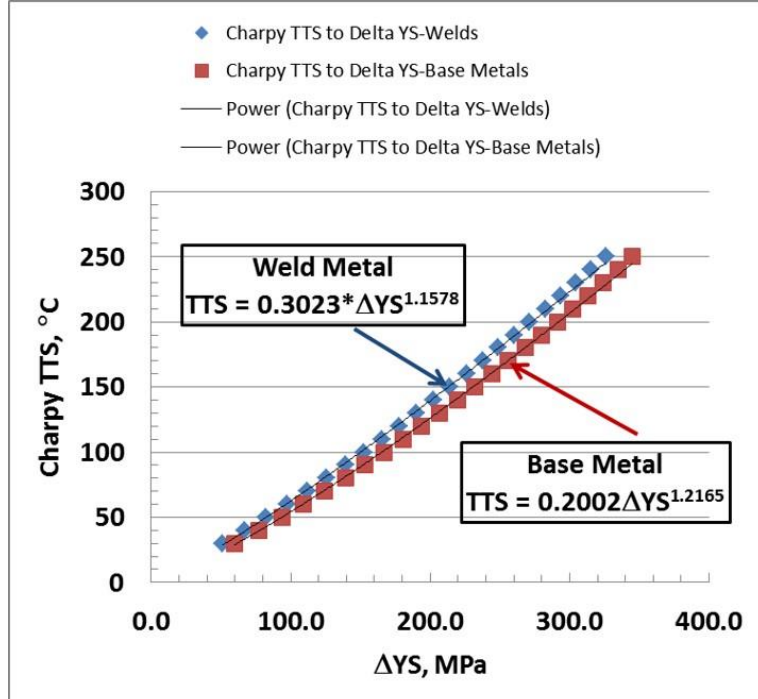

(b)

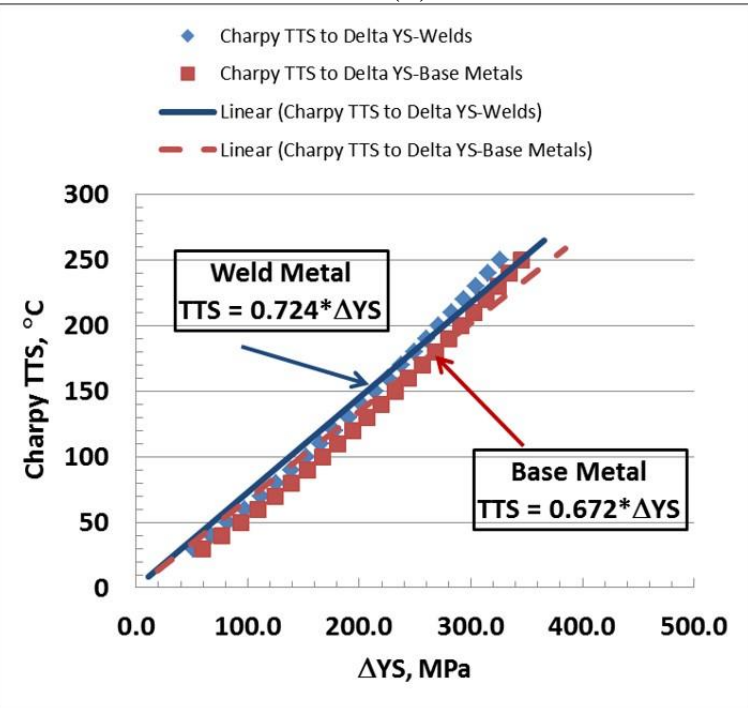

Figure 5.4. Power law (a) and linear (b) fits to data from original equations in [16] for $\Delta \sigma_{y}$, to $\Delta \mathrm{TT}_{41 \mathrm{~J}}$.

(a)

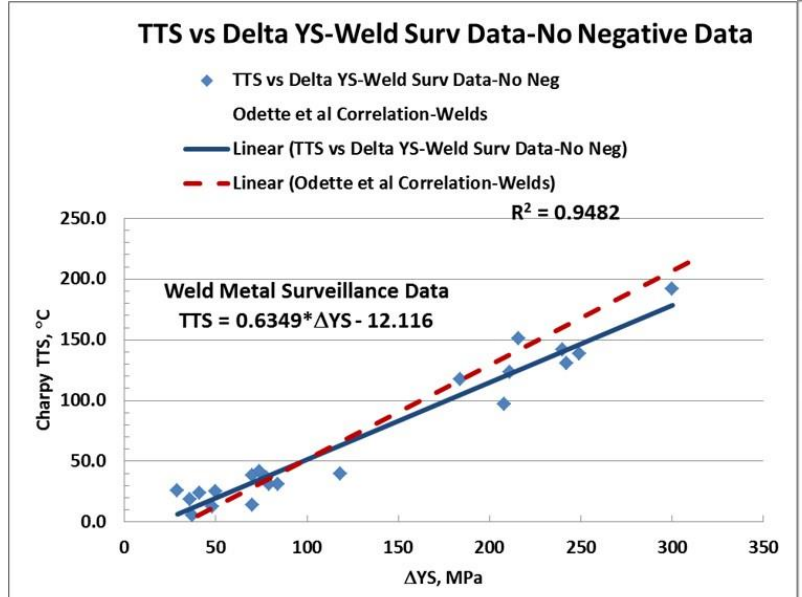

(b)

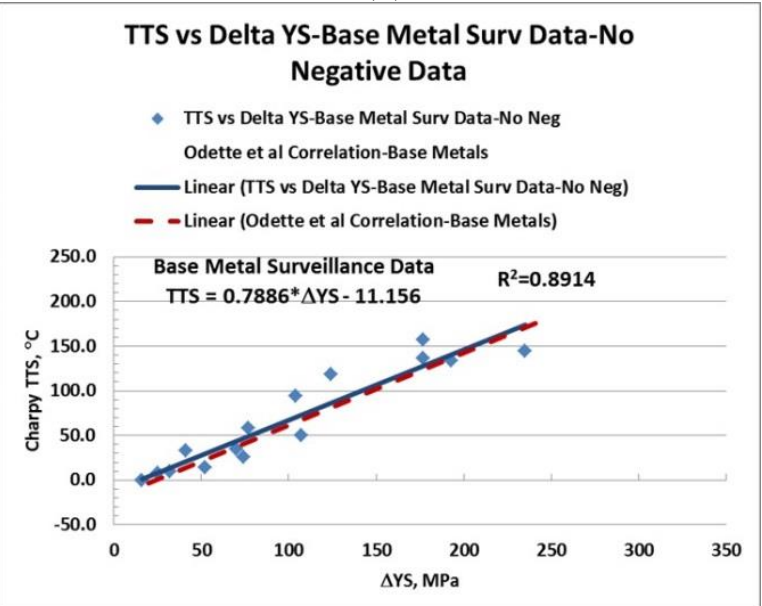

TTS vs Delta YS-Base Metal Surv Data-No Negative Data Odette et al Correlation-Base Metals

- Linear (TTS vs Delta YS-Base Metal Surv Data-No Neg)

- Linear (Odette et al Correlation-Base Metals)

Figure 5.5. Charpy 41-J shifts vs yield strength changes for (a) weld metal and (b) base metal surveillance data for the nine surveillance materials.

The microhardness, shear punch, and tensile tests for the ATR-2 experiment have been performed at room temperature, while some surveillance tensile datasets do not have results for tests at room temperature. Thus, to make comparisons with RPV surveillance data, the surveillance tensile data require interpretation to obtain room temperature yield strength for each fluence condition and to enable calculations of the yield strength changes. Figure 5.6 (a) shows the surveillance tensile data for Material F, the lower copper Weld Heat 1P3571 and linear fits to the data used to estimate the yield strength at room temperature by extrapolation in cases where there are no room temperature data. Generally, a 2nd order polynomial was used, but a linear fit was sometimes required to obtain a sensible result due to sparse data. Figure 5.6 (b) shows the resulting estimates of room temperature yield strength (the fluences are offset slightly to enable visualizing the tensile and SPT data). In this case, the microhardness predicted increase is greater than those from SPT or measured yield strength; however, as will be seen later with graphs of Charpy 41-J increases vs fluence, that is not always the case. 
ORNL/TM-2017/172

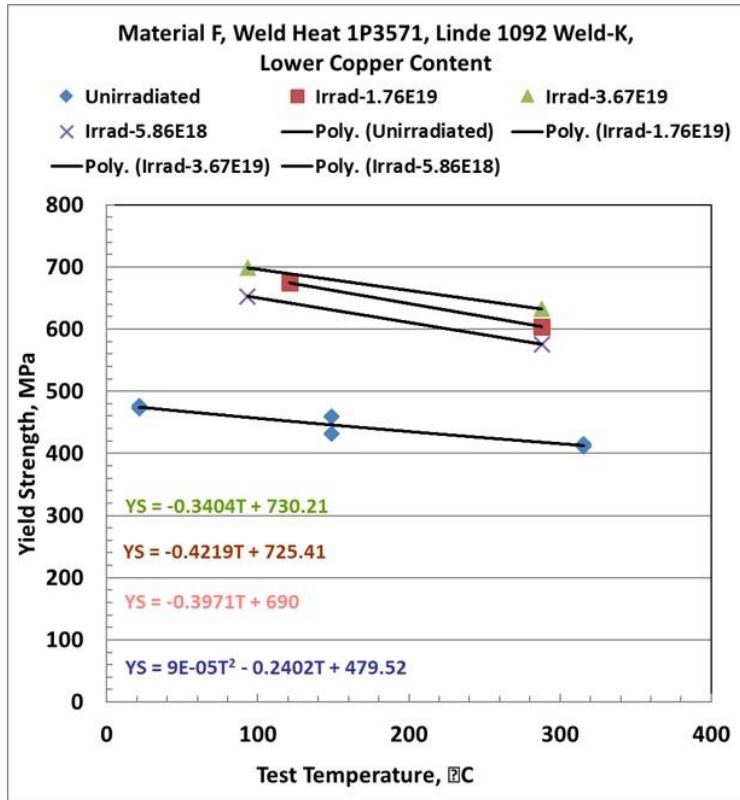

(a)
Material F, Weld Heat 1P3571, Linde 1092 Weld-K, Lower Copper Content

- Linde 1092-K Weld Tensile Data $\quad$ ATR-2 Microhardness Prediction $\triangle$ ATR-2 Tensile $\quad \times$ ATR-2 SPT

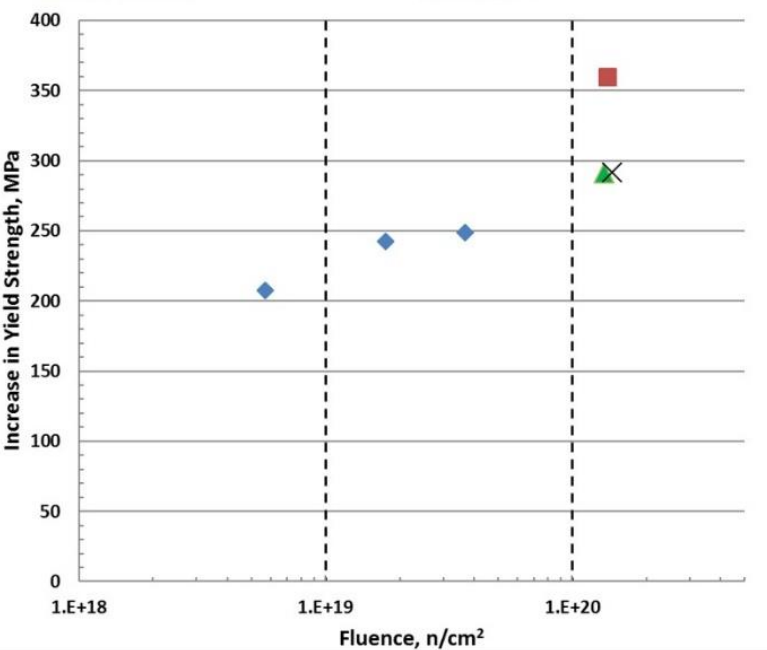

(b)

Figure 5.6. Tensile yield strength from surveillance reports with linear curve fits (a), and estimated room temperature yield strength increases vs fluence compared with ATR-2 results (b), for Material F, the lower copper Weld Heat 1 P3571.

Charpy impact surveillance data have been gleaned from the REAP database and from selected surveillance reports to enable comparisons of the irradiation-induced 41-J transition temperature shifts with the predictions from the ATR-2 experiment. Figures 5.7-5.15 provide the comparisons for the nine surveillance materials. Note that some of the figures include estimates based on the estimated room temperature tensile yield strengths as discussed relative to Figure 5.6; in those cases, shift was estimated by $\Delta T T_{41 J}=0.7^{*} \Delta \sigma_{y}$. For Material A, Weld Heat $33 \mathrm{~A} 277$ in Fig. 5.7, the shifts thus predicted from surveillance tensile data are mostly underpredicted, while for the other eight materials, the shifts are mostly overpredicted. More detailed analysis of the surveillance database may enable improved correspondence between such predictions and measurements.

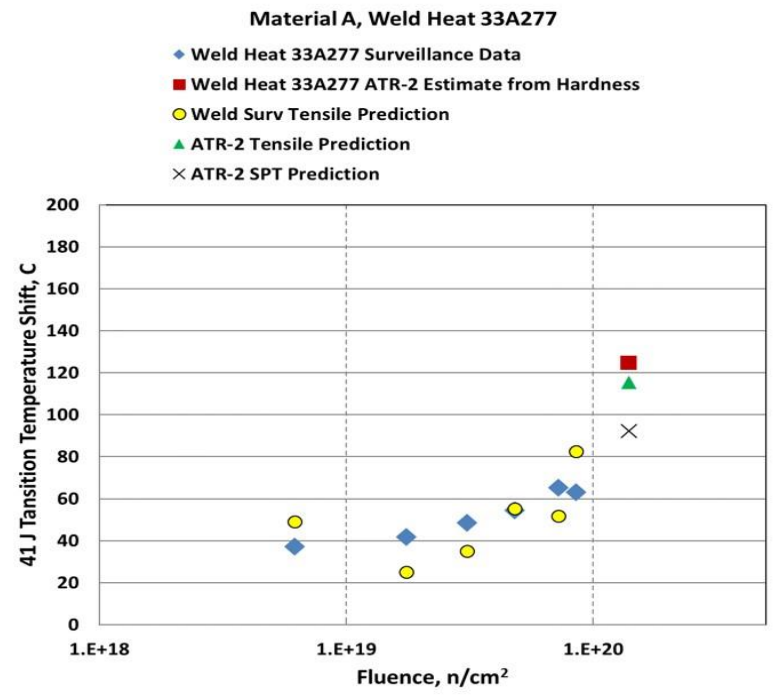

Figure 5.7. Irradiation-induced Charpy 41-J transition temperature shifts for measured surveillance data and for the predicted shifts from the ATR-2 experiment for Material A, Weld Heat 33A277. 


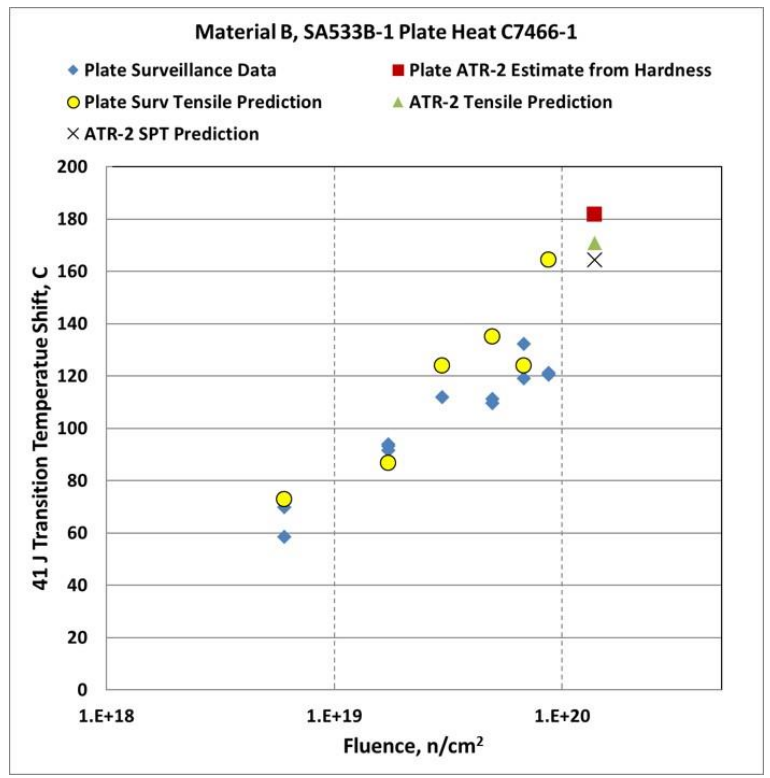

Figure 5.8. Irradiation-induced Charpy 41-J transition temperature shifts for measured surveillance data and for the predicted shifts from the ATR-2 experiment for Material B, SA533B-1 Plate, Heat C7466-1.

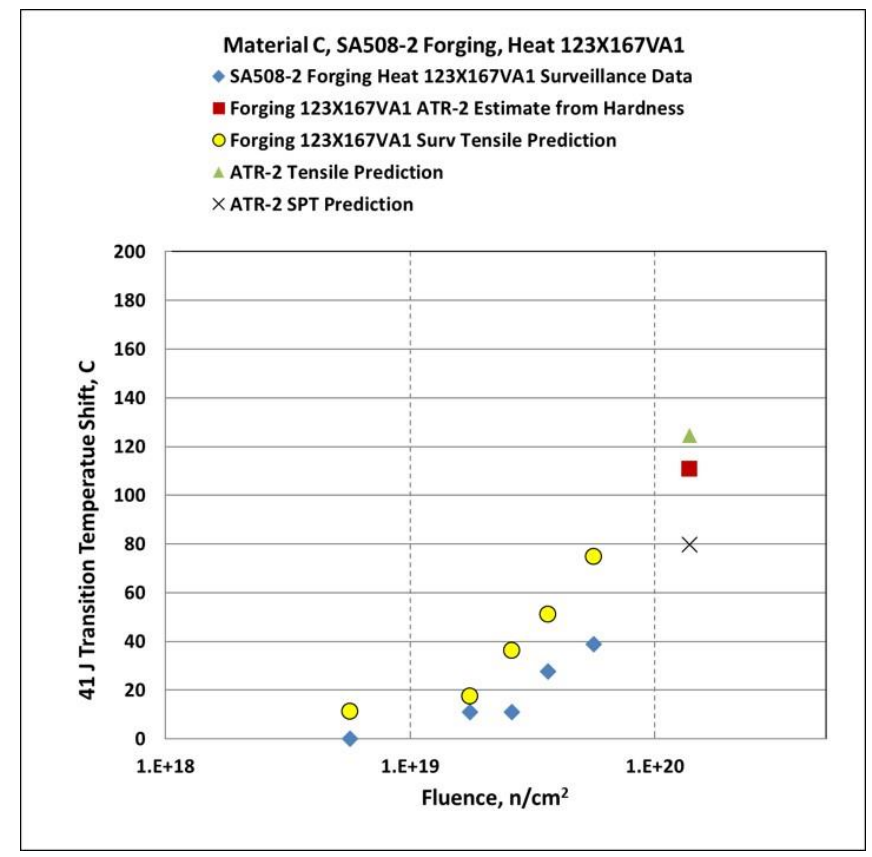

Figure 5.9. Irradiation-induced Charpy 41-J transition temperature shifts for measured surveillance data and for the predicted shifts from the ATR-2 experiment for Material C, SA508-2 Forging Heat 123X167VA1. 


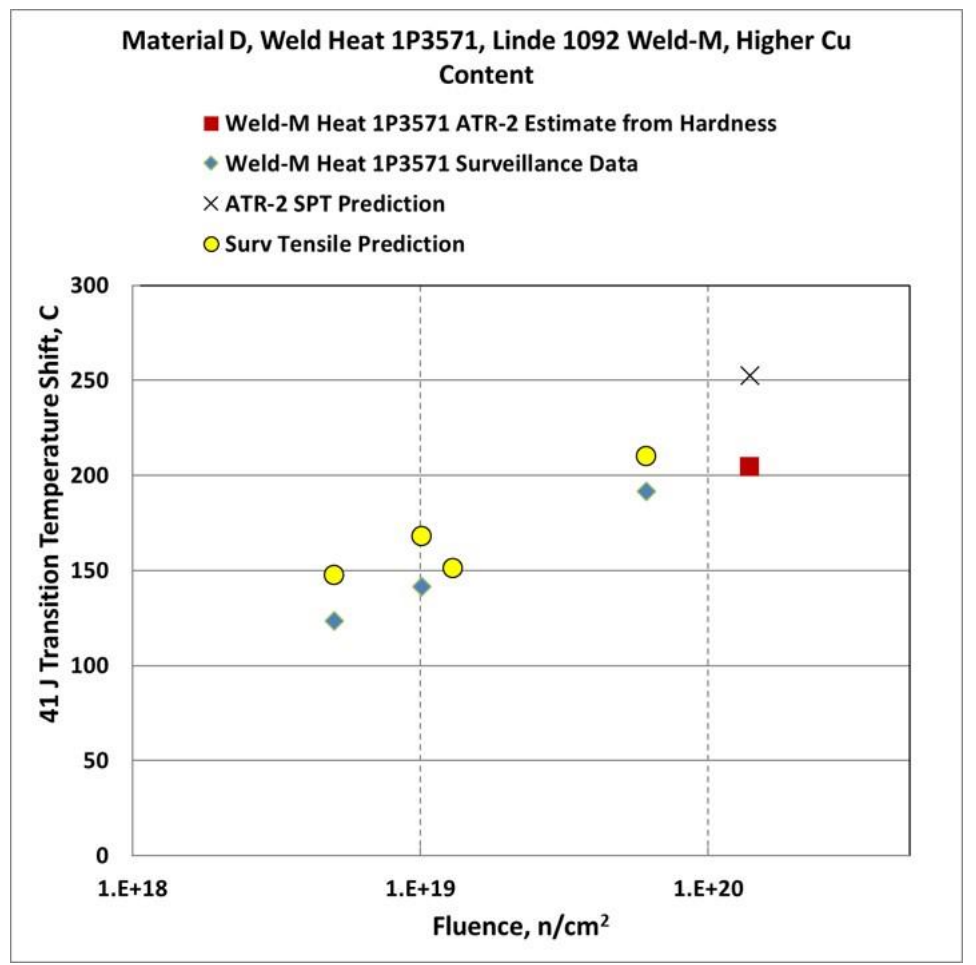

Figure 5.10. Irradiation-induced Charpy 41-J transition temperature shifts for measured surveillance data and for the predicted shifts from the ATR-2 experiment for Material D, Weld Heat 1P3571, Linde 1092 Weld-M, Higher Copper.

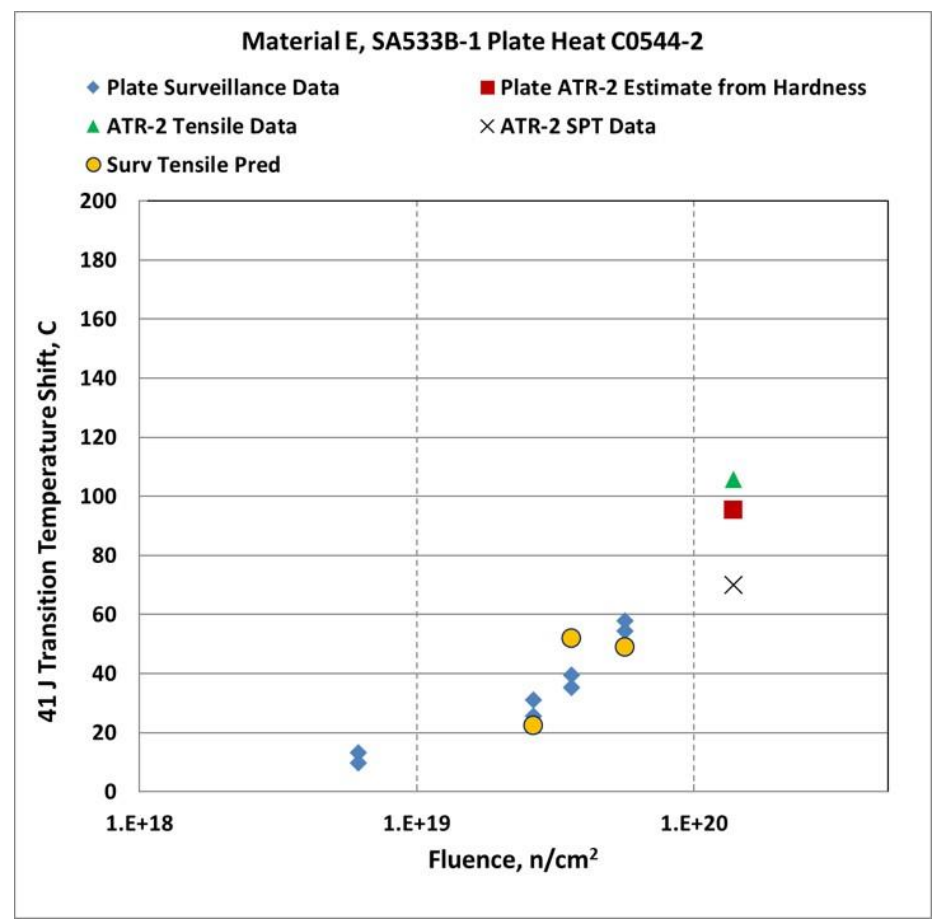

Figure 5.11. Irradiation-induced Charpy 41-J transition temperature shifts for measured surveillance data and for the predicted shifts from the ATR-2 experiment for Material E, SA533B-1 Heat C0544-2, Plate B9004-2. 


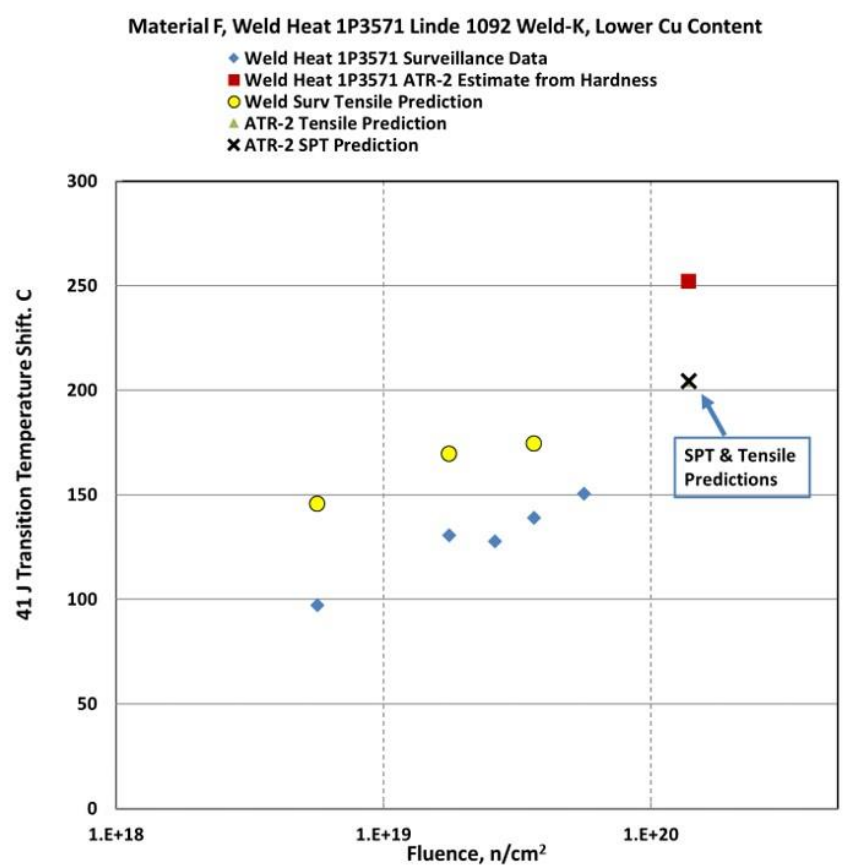

Figure 5.12. Irradiation-induced Charpy 41-J transition temperature shifts for measured surveillance data and for the predicted shifts from the ATR-2 experiment for Material F, Weld Heat 1P3571, Linde 1092 Weld-K, Lower Copper.

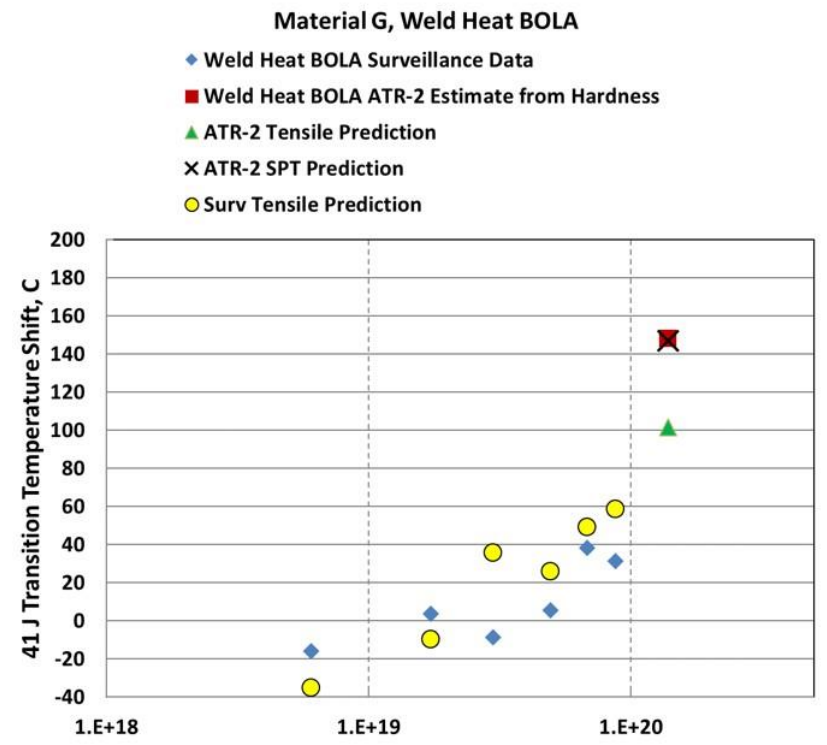

Fluence, $\mathrm{n} / \mathrm{cm}^{2}$

Figure 5.13. Irradiation-induced Charpy 41-J transition temperature shifts for measured surveillance data and for the predicted shifts from the ATR-2 experiment for Material G, Weld Heat BOLA. 


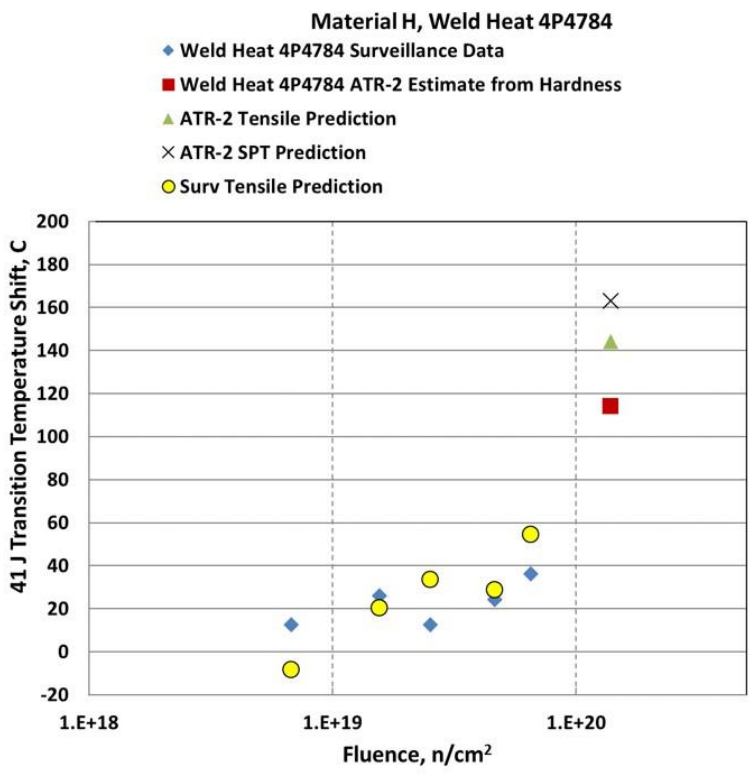

Figure 5.14. Irradiation-induced Charpy 41-J transition temperature shifts for measured surveillance data and for the predicted shifts from the ATR-2 experiment for Material H, Weld Heat 4P4784.

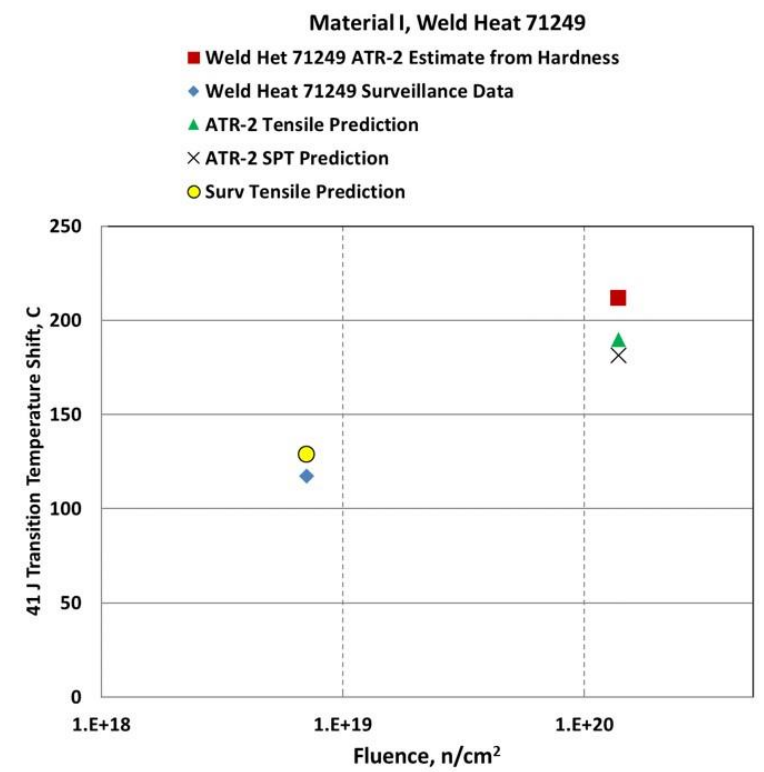

Figure 5.15. Irradiation-induced Charpy 41-J transition temperature shifts for measured surveillance data and for the predicted shifts from the ATR-2 experiment for Material I, Weld Heat 71249.

It can be seen from inspection of the above figures that the shift predictions from the ATR-2 tests are mixed relative to the tensile predicted shift values. The hardness predictions are generally higher than those from the ATR-2 tensile predictions, while the SPT predictions are generally lower than those from the ATR-2 tensile predictions.

Figure 5.16from [15] shows $\Delta \sigma_{\mathrm{y}}$ versus fluence for the nine surveillance alloys having either low $\mathrm{Cu}$ (left $<0.07)$ or higher $\mathrm{Cu}$ (right $>0.07)$. The data at lower fluence $\left(<1 \times 10^{20} \mathrm{n} / \mathrm{cm}^{2}\right)$ are from 
ORNL/TM-2017/172

the RPV surveillance programs and the highest fluence data points are from the ATR-2 irradiation. For the low $\mathrm{Cu}$ steels (Materials $\mathrm{C}, \mathrm{E}, \mathrm{G}, \mathrm{H}$ ), the $\Delta \sigma_{\mathrm{y}}$ generally increases approximately linearly with fluence. The higher $\mathrm{Cu}$ steels (Materials $\mathrm{A}, \mathrm{B}, \mathrm{D}, \mathrm{F}, \mathrm{I}$ ) show a large increase in $\Delta \sigma_{\mathrm{y}}$ at low fluence followed by a steady or slightly accelerated increase to the ATR-2 condition. Effects of $\mathrm{Cu}$ and $\mathrm{Ni}$ are observed in both cases, and the lower $0.14 \% \mathrm{Cu}, 0.19 \% \mathrm{Ni}$ steel (Material A) hardens much less than the others with higher concentrations of these solutes [15]. From [15], Figure shows the measured hardening from ATR-2 cup 7 for various materials in the existing commercial reactor surveillance database (the nine materials discussed in this report are not included in the figure) along with predictions from the Eason-Odette-Nanstad-Yamamoto (EONY) [1] and ASTM E900 [2] models, as well as a $\Delta \sigma_{\mathrm{y}}$ model derived from the UCSB Irradiation Variables (IVAR) database [18]. In the case of both EONY and E900 the $\Delta \mathrm{T}$ predictions have been converted to $\Delta \sigma_{\mathrm{y}}$ using established correlations [15]. With few exceptions, the models under-predict the high fluence ATR-2 data. The underpredictions are as much as $129 \mathrm{MPa}$, averaging 62 and $54 \mathrm{MPa}$ for EONY and E900, respectively. The under-predictions for the IVAR model are generally slightly less, averaging $45 \mathrm{MPa}$. Again, these comparisons do not account for potential flux effects. A major focus of future work will be on PIE on lower fluence ATR-2 conditions to more directly bridge to the surveillance data and help to better understand flux effects. In addition to the mechanical property tests reported here, and as discussed in [15], various microstructural evaluations will be performed with these materials to ascertain the features responsible for the material embrittlement to enable informed development of predictive models applicable to high fluence conditions. As mentioned earlier, this will include critical evaluations of the influence of neutron flux as well.
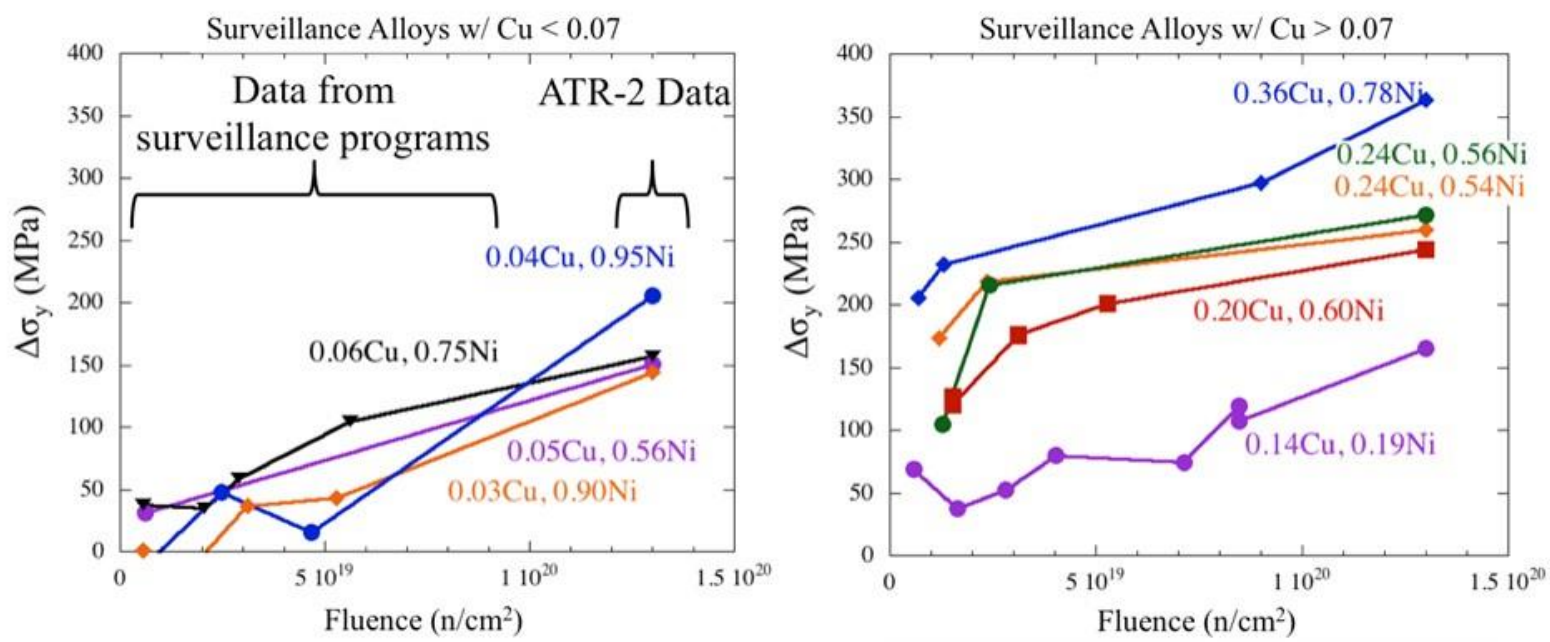

Figure 5.16. $\Delta \sigma_{\mathrm{y}}$ versus fluence for the nine surveillance alloys with $\langle 0.07 \mathrm{wt} . \% \mathrm{Cu}(\mathrm{left})$ and $\rangle$ 0.07 wt. \% Cu (right). [15] 


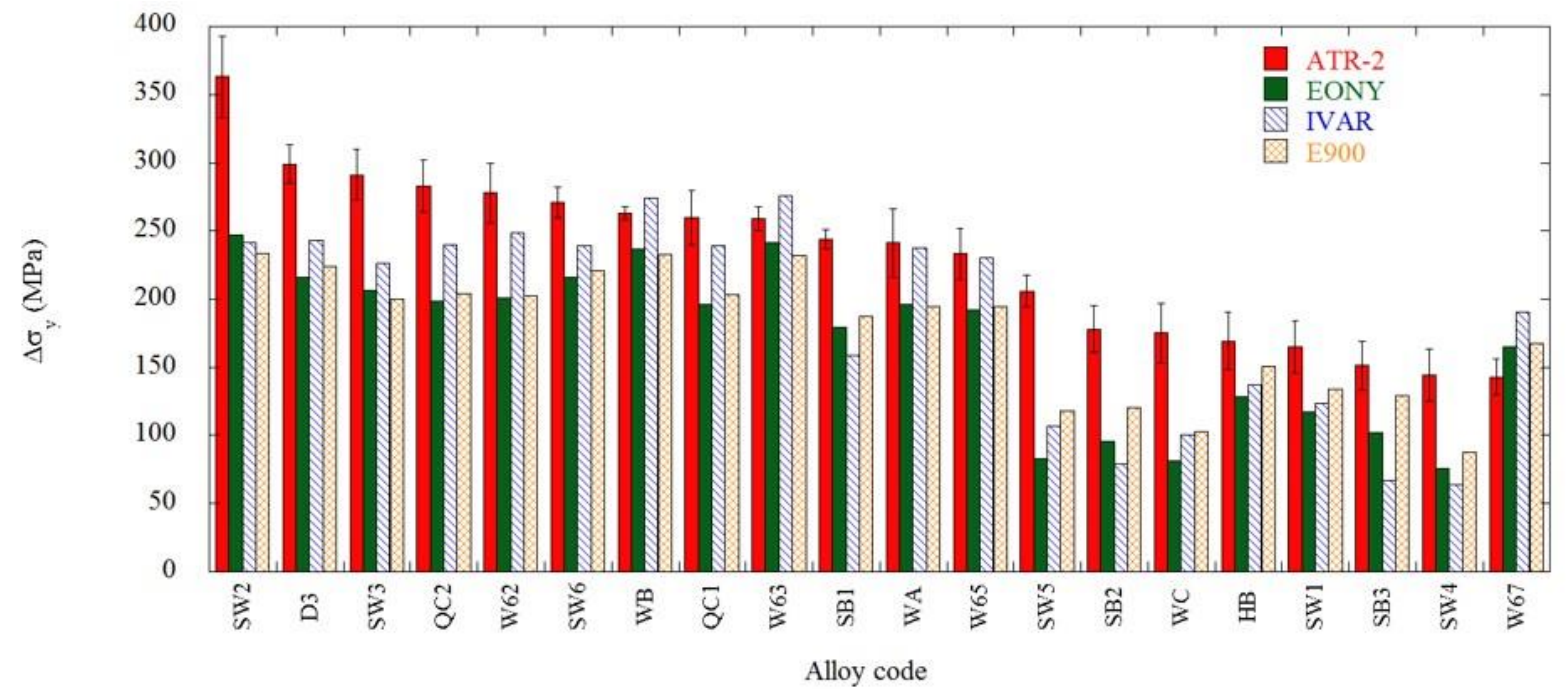

Figure 5.17. ATR-2 cup 7 hardening for various surveillance alloys along with predictions from existing models. [15]

\section{SUMMARY}

The primary objective of the LWRSP RPV task is to develop robust predictions of transition temperature shifts (TTS) at high fluence $(\phi t)$ to at least $10^{20} \mathrm{n} / \mathrm{cm}^{2}(\mathrm{E}>1 \mathrm{MeV})$ pertinent to plant operation of some pressurized water reactors (PWR) for 80 full power years. The RPV task of the LWRS Program is working with various organizations to obtain archival surveillance materials from commercial nuclear power plants to allow for comparisons of the irradiation-induced microstructural features from reactor surveillance materials with those from similar materials irradiated under high flux conditions in test reactors. Specifically, nine commercial reactor RPV surveillance materials were obtained with cooperation from various nuclear industry organizations, EPRI, and ATIConsulting. Additionally, the task is collaborating and cooperating with the University of California Santa Barbara regarding post-irradiation examination of the materials and specimens in the ATR-2 experiment. The ATR-2 capsule completed irradiation on 17 January 2014 with the average and peak fluences at the end of cycle $155 \mathrm{~A}$ of 1.0 and $1.39 \times 10^{20} \mathrm{n} / \mathrm{cm}^{2}(\mathrm{E}>1 \mathrm{MeV})$, respectively. The capsule was disassembled at INL and 13 specimen cups were shipped to ORNL with arrival at the Irradiated Materials Examination and Testing facility hot cells on 10 July 2015. This report has summarized the experiment, a detailed description of the specific nine commercial reactor RPV materials obtained, the test specimens, and the post-irradiation activities completed to date by ORNL and UCSB. In general, these preliminary results from microhardness, tensile, and shear punch tests indicate continued embrittlement for most of the materials tested, with some acceleration of embrittlement with fluence indicated for lower copper materials, implying influence of so-called late-blooming phases (Ni-Mn-Si precipitates). The Charpy 41-J shift predictions from the ATR-2 tests are mixed relative to the tensile predicted shift values. The hardness predictions are generally higher than those from the ATR-2 tensile predictions, while the SPT predictions are generally lower than those from the ATR-2 tensile predictions. Detailed microstructural investigations will be used to ascertain the features responsible for high fluence embrittlement. Given that the surveillance database is much larger than that used to develop the existing correlations for estimating Charpy 41-J shift from yield strength increases, an updated analysis of the surveillance database may enable improved correspondence between such predictions and measurements. 


\section{REFERENCES}

1. Eason, E. D., G. R. Odette, R. K. Nanstad and T. Yamamoto, "A physically-based correlation of irradiation-induced transition temperature shifts for RPV steels," Journal of Nuclear Materials, Volume 433, Issues 1-3, February 2013, Pages 240-254. Also in: Eason, E. D., Odette, G. R., Nanstad, R. K. and Yamamoto, T., "A Physically Based Correlation of Irradiation-Induced Transition Temperature Shifts for RPV Steels," ORNL/TM-2006/530, Oak Ridge National Laboratory, February 2007.

2. ASTM E900-15, "Standard Guide for Predicting Radiation-Induced Transition Temperature Shift in Reactor Vessel Materials,” ASTM International, West Conshohocken, PA, 2015.

3. Nanstad, R. K. and Odette, G. R., "Reactor Pressure Vessel Issues for the Light-Water Reactor Sustainability Program," Proceedings of Env. Deg. Conf., 2009.

4. Odette, G. R. and Nanstad, R. K., "Predictive Reactor Pressure Vessel Steel Irradiation Embrittlement Models: Issues and Opportunities,” J. Metals, 61, 7, July 2009.

5. M.K. Miller, K.A. Powers, R.K. Nanstad, and P. Efsing, "Atom probe tomography characterizations of high nickel, low copper surveillance RPV welds irradiated to high fluences," J. Nuc. Mat., 437 (2013) 107-115.

6. Nanstad, R. K., G. R. Odette, and T. Yamamoto, "Progress Report on Disassembly of UCSB ATR-2 Capsule and Revision to Post-Irradiation Plan," ORNL/TM-2014/525, Oak Ridge National Laboratory, September 2014.

7. Nanstad, R. K. and G. R. Odette, "Reactor Pressure Vessel Task of Light Water Reactor Sustainability Program: Milestone Report on Materials and Machining of Specimens for the ATR-2 Experiment," ORNL/LTR-2011/413, Oak Ridge National Laboratory, January 2011.

8. Nanstad, R. K., "Reactor Pressure Vessel Task of Light Water Reactor Sustainability Program: Assessment of High Value Surveillance Materials," ORNL/LTR-2011/172, Oak Ridge National Laboratory, June 2011.

9. Nanstad, R. K., G. R. Odette, T. Yamamoto and M. A. Sokolov, "Post-irradiation Examination Plan for ORNL and University of California Santa Barbara Assessment of UCSB ATR-2 Irradiation Experiment," ORNL/TM-2013/598, Oak Ridge National Laboratory, December 2013.

10. “As-Run Source Term for the UCSB-2 Leadout Experiment in I-22”, ECAR No. 2426, Idaho National Laboratory, February 13, 2014.

11. "As-Run Thermal Analysis of the UCSB-2 Experiment in the ATR," 2016; ATR NSUF ECAR No. 3218, Project No. 30946

12. "As-Run Physics Analysis for the UCSB-2 Leadout Experiment in I-22," 2016; ATR NSUF ECAR No. 3219, Project No. 30946.

13. "Reactor Embrittlement Archive Project", Oak Ridge Natl. Lab., https://reap.ornl.gov. 14. Milot TS. "Establishing Correlations for Predicting Tensile Properties Based on the 
ORNL/TM-2017/172

Shear Punch Test and Vickers Microhardness Data" [PhD Thesis]. University of California, Santa Barbara, 2013.

15. Odette, G. R., et. al, "Update on the High Fluence Advanced Test Reactor - 2 Reactor Pressure Vessel High Fluence Irradiation Project," UCSB ATR-2 2016-1, LWRS Report Number M3LW-16OR0402012, University of California, Santa Barbara, 30 June 2016. https://lwrs.inl.gov/SitePages/Home.aspx

16. Odette, G.R., et. al., "The Effects of Composition and Heat Treatment on Hardening and Embrittlement of Reactor Pressure Vessel Steels," NUREG-CR-6778, University of California at Santa Barbara, May 2003.

17. Nanstad, R. K. and Berggren, R. G., "Effects of Irradiation Temperature on Charpy and Tensile Properties of High-Copper, Low Upper-Shelf, Submerged-Arc Welds," STP1175 Effects of Radiation on Materials: 16th International Symposium, Eds. Kumar AE, Gelles DS, Nanstad RK, Little TA, ASTM International, West Conshohocken, PA, January 1994.

18. G.R. Odette et al., "The Irradiation Variables (IVAR) Program Database on Irradiation Induced Yield and Ultimate Tensile Stress Changes in Reactor Pressure Vessel Steels," UCSB MRPG PV1-2009 (Santa Barbara, CA: UES Materials Reliability and Performance Group, UCSB, 2009). 


\title{
INTERNAL DISTRIBUTION
}

\author{
Busby, J.T. \\ Chen, $X$. \\ Leonard, K.J. \\ Nanstad, R.K. \\ Robertson, J.P. \\ Rosseel, T.M. \\ Sokolov, M.A. \\ Tan, L. \\ Williams Jr, D.L.
}

\section{EXTERNAL DISTRIBUTION}

N. Almirall, Department of Mechanical Engineering, University of California, Santa Barbara, CA 93106, (nathanalmirall@umail.ucsb.edu)

T. Hardin, Electric Power Research Institute, 3420 Hillview Avenue | Palo Alto, CA 94304

(thardin@epri.com)

G. R. Odette, Department of Mechanical Engineering, University of California, Santa Barbara, CA 93106 (odette@engineering.ucsb.edu)

W. L. Server, ATI-Consulting, P.O. Box 879, Black Mountain, NC 28711

(wserver@ati-consulting.com)

T. Yamamoto, Department of Mechanical Engineering, University of California, Santa

Barbara, CA 93106 (yamataku@engineering.ucsb.edu)

J. Wagner, Idaho National Laboratory, P.O. Box 1625, Idaho Falls, ID 83415-3860, (john.wagner@inl.gov)

P. Wells, Department of Mechanical Engineering, University of California, Santa Barbara, CA 93106, (Peter Wells well7765@gmail.com)

R. Reister, GTN Bldg, 1000 Independence Ave, S.W. Washington, DC 20585, (Richard.Reister@nuclear.energy.go 